\title{
The NASA High Speed ASE Project: Computational Analyses of a Low-Boom Supersonic Configuration
}

\author{
Walter A. Silva*1, Antonio De La Garza ${ }^{\dagger 2}$, Scott Zink ${ }^{\ddagger 2}$, Elias G. Bounajem ${ }^{\S 2}$, J. \\ Christopher Johnson ${ }^{\llbracket 2}$, Michael Buonanno ${ }^{\| 3}$, Mark D. Sanetrik**1, Seung Y. Yoo ${ }^{\dagger \dagger 4}$, \\ George Kopasakis ${ }^{\ddagger 5}$, David M. Christhilf ${ }^{6}$, and Pawel Chwalowski ${ }^{1}$ \\ ${ }^{1}$ NASA Langley Research Center, Hampton, VA \\ ${ }^{2}$ Lockheed-Martin Aeronautics Company, Ft. Worth, TX \\ ${ }^{3}$ Lockheed-Martin Aeronautics Company, Palmdale, CA \\ ${ }^{4}$ NASA Dryden Flight Research Center, Edwards, CA \\ ${ }^{5}$ NASA Glenn Research Center, Cleveland, $\mathrm{OH}$ \\ ${ }^{6}$ TEAMS-2, Hampton, VA
}

\begin{abstract}
A summary of NASA's High Speed Aeroservoelasticity (ASE) project is provided with a focus on a low-boom supersonic configuration developed by Lockheed-Martin and referred to as the $\mathrm{N}+2$ configuration. The summary includes details of the computational models developed to date including a linear finite element model (FEM), linear unsteady aerodynamic models, structured and unstructured CFD grids, and discussion of the FEM development including sizing and structural constraints applied to the $\mathrm{N}+2$ configuration. Linear results obtained to date include linear mode shapes and linear flutter boundaries. In addition to the tasks associated with the $\mathrm{N}+2$ configuration, a summary of the work involving the development of AeroPropulsoServoElasticity (APSE) models is also discussed.
\end{abstract}

\section{Introduction}

The unique, slender configuration of low boom aircraft, combined with nonlinear aerodynamics and rigid body effects, often results in highly complex nonlinear, aeroelastic/flight dynamics phenomena. These aeroelastic phenomena can affect ride quality, gust loads, flutter, flight dynamics and control, and engine performance. The aeroelastic/flight dynamics phenomena simultaneously influence the airframe and propulsion system controls, producing undesirable effects on performance and flying characteristics.

These aeroservoelastic (ASE) phenomena need to be thoroughly understood for supersonic flight to be safe, efficient, and comfortable. In addition, there is an opportunity, through active controls, to exploit these phenomena for improved performance and efficiency. Analysis and design capabilities for slender supersonic aircraft may then be enhanced by including this new knowledge.

A vast body of analytical, computational, wind-tunnel and flight data exist on the ASE characteristics of subsonic transport and supersonic fighter aircraft. ${ }^{1}$ Systems for control of undesirable aeroelastic phenomena, such as suppression of flutter, have been demonstrated in the past. ${ }^{2,3,4,5}$ Systems that exploit vehicle

\footnotetext{
* Senior Research Scientist, Aeroelasticity Branch, AIAA Associate Fellow.

${ }^{\dagger}$ Aeronautical Engineer Staff, AIAA Senior Member.

$¥$ Aeronautical Engineer Staff, AIAA Associate Fellow.

$\S$ Aerospace Engineer, AIAA Member.

"Aeronautical Engineer Staff, AIAA Member.

$\|_{\text {Aeronautical Engineer Staff, AIAA Senior Member. }}$

**Aerospace Engineer, Aeroelasticity Branch, AIAA Senior Member.

${ }^{\dagger \dagger}$ Aerospace Engineer, Control and Dynamics Branch, AIAA Senior Member.

$\ddagger \ddagger$ Aerospace Engineer, Controls and Dynamics Branch, AIAA Senior Member.

Controls Engineer.

Aerospace Engineer, Aeroelasticity Branch, AIAA Senior Member.
} 
flexibility for improved performance, such as vehicle roll control beyond aileron reversal and wing load alleviation have also been demonstrated..$^{6,7}$

Considerably less data are available for supersonic cruise configurations. In the mid- to late-1990s, as part of the High Speed Research (HSR) program, research was performed in the areas of computational and experimental aeroelasticity. ${ }^{8}$ As part of this research, aeroelastic wind-tunnel models were designed, built, and tested in the Transonic Dynamics Tunnel (TDT). A remnant from the HSR program is the Semi-Span Super-Sonic Transport (S4T) ${ }^{9}$ a very sophisticated, aeroelastically-scaled semispan wind-tunnel model based on the Technology Concept Aircraft (TCA) configuration equipped with three active surfaces (ride control vane, aileron, horizontal tail) and flow-through nacelles with flexible mounts. The model was designed so that it would flutter within the TDT operating boundary, making it an ideal testbed for investigating ASE issues associated with supersonic cruise configurations.

Under the auspices of the Supersonics Project under NASA's Fundamental Aeronautics Program (FAP), the S4T was the subject of four experiments in the TDT: two open-loop (no feedback control) tests and two closed-loop (with feedback control) tests over the span of three years between 2007 and 2010. A special session on the various aspects of the S4T program was organized for the AIAA Structures, Structural Dynamics, and Materials (SDM) conference held in 2012. The work involving the S4T was completed in 2012.

The Supersonics Program was renamed the High Speed Program. The High Speed Program, still a component of NASA's Fundamental Aeronautics Program (FAP), continues the original charter of the Supersonics Program, addressing the technical barriers to safe, efficient, and economical supersonic flight. One of the projects within the High Speed Program is the Aeroservoelasticity (ASE) project, tasked with addressing the aeroelastic (AE), aeroservoelastic (ASE), and aeropropulsoservoelastic (APSE) challenges associated with low-boom supersonic configurations. To address more realistic challenges associated with a full-span configuration, including rigid-body modes, the High Speed ASE project is now focusing on a full-span low-boom configuration.

A top priority for the High Speed ASE project is to develop the tools required to perform accurate, high fidelity computational AE, ASE, and APSE analyses in support of the design of future low-boom high speed civil aircraft. As a means of accomplishing that priority, the High Speed Program is working with Lockheed-Martin to conduct such analyses. Under the NASA N+2 (two generations from present state) contract, Lockheed-Martin has developed a low-boom supersonic configuration and a detailed finite element model (FEM). An artist rendering of two views of the Lockheed-Martin $\mathrm{N}+2$ configuration are presented in Figure 1 and Figure 2. The goal of the $\mathrm{N}+2$ effort is to develop and validate technologies for future civil supersonic airliners. Primary activities under this effort included Low-Boom Wind-Tunnel Testing, Propulsion System Maturation, Optimization Method Development, Structural and Aeroelastic Analysis, and System Studies.

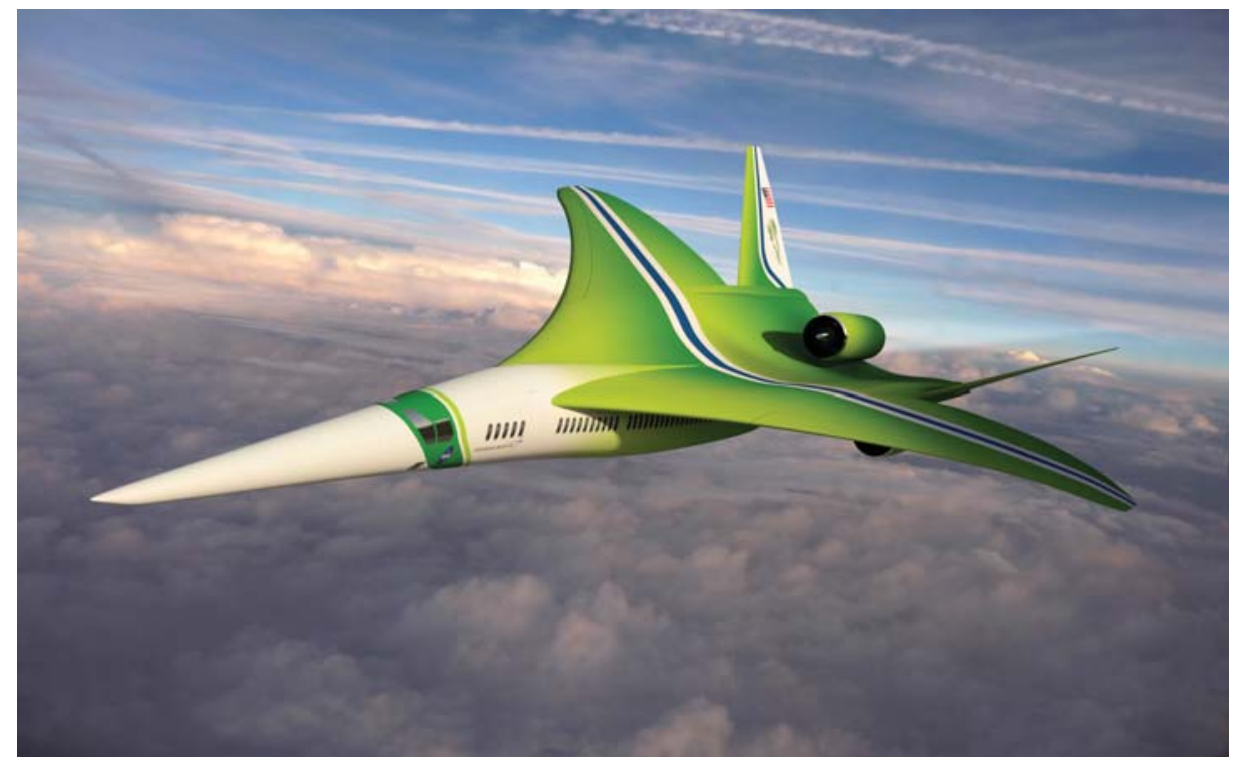

Figure 1. Artist's concept of the Lockheed-Martin N+2 configuration. 


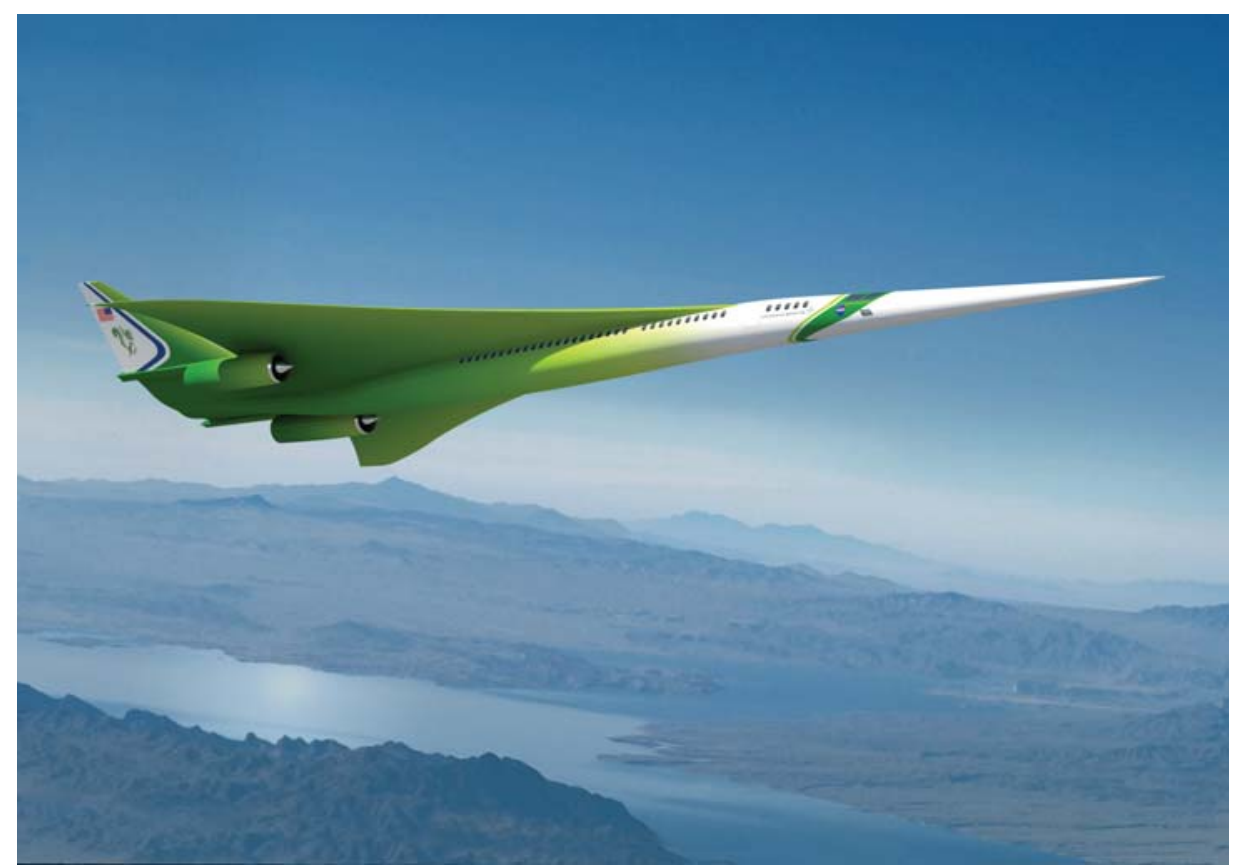

Figure 2. Artist's concept of the Lockheed-Martin N+2 configuration.

In addition to the analysis of the N+2 configuration, the High Speed - ASE project is also involved in the development of APSE models. The development of an APSE model consists of the interconnection of a traditional ASE model (airframe model) with a dynamic engine model. Traditionally, these two models are developed and used separately by distinct disciplines (such as ASE and propulsion performance). The ultimate goal of this development is to be able to determine if the airframe flexibility has an effect on the thrust dynamics of the propulsion system, coupling back to the airframe flexibility modes as a closed loop system, in order to study performance such as vehicle stability and ride quality.

The paper begins with a description of the $\mathrm{N}+2$ configuration followed by a description of the structural sizing and analysis leading to a finite element model (FEM). Preliminary linear aeroelastic analyses are presented and discussed. Structured and unstructured grids of the $\mathrm{N}+2$ configuration are presented and associated issues are discussed. Finally, a summary of the work being performed in the area of APSE model development is also discussed.

\section{N+2 Configuration}

In this section, general performance characteristics of the $\mathrm{N}+2$ configuration are presented. Presented in Figure 3 are four different views: a planform view (Figure 3(a)), a side view (Figure 3(b)), an isometric view (Figure 3(c)), and a front view (Figure 3(d)). Of particular interest are the three engines, one mounted aft and on top while the other two are mounted below and close to the fuselage. From an aeroelastic point of view, this arrangement would not seem to pose any obvious aeroelastic issues. In fact, the two engines mounted below offer some relief from possible aeroelastic issues by being installed close to the fuselage instead of further out on the span of the wing. However, having these large masses at the tail of a flexible fuselage is likely to cause some aeroelastic issues. 


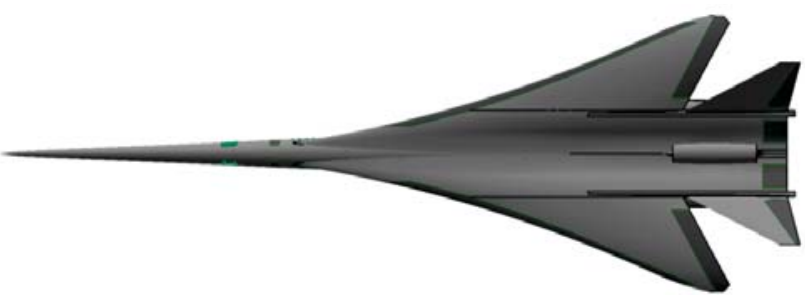

(a) Planform view.

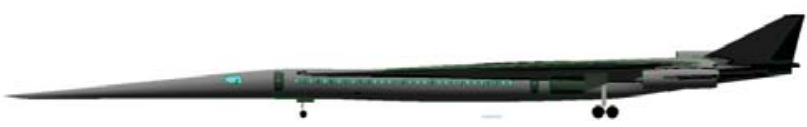

(b) Side view.

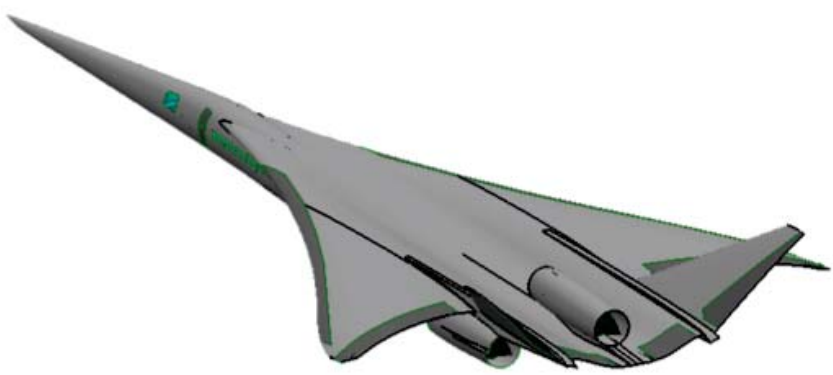

(c) Isometric view.

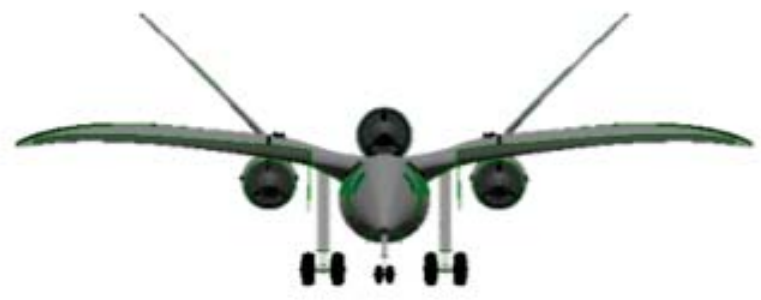

(d) Front view.

Figure 3. Different views of the $\mathrm{N}+2$ configuration.

Presented in Table 1 are the general characteristics of the vehicle. At a length of $244 \mathrm{ft}$., the $\mathrm{N}+2$ configuration is about $21 \%$ longer than the Concorde but at about the same wingspan. However, the $\mathrm{N}+2$ configuration is lighter than the Concorde, with a cruising Mach number of 1.7 that is lower than that of the Concorde (cruise $\mathrm{M}=2.02$ ), but with a greater range.

\section{Structural Layout and FEM}

As a first step towards performing realistic aeroelastic analyses, Lockheed-Martin developed a detailed structural layout of the configuration. Presented in Figure 4 is a sample image of the substructure of the vehicle. The goal of the finite element modeling effort was to develop a structural model with a representative global stiffness and mass distribution to enable aeroelastic studies. To facilitate the use of high fidelity CFD based methods, a detailed structural layout was developed, meshed, and structurally optimized to a representative set of load cases consisting of landing, maneuver, and gust loads, subject to strain, buckling, and minimum gauge criteria. A combined image of all of the substructural components of the vehicle is 
Table 1. Configuration 1044

\begin{tabular}{|c|c|}
\hline Length & 244 ft. \\
\hline Span & $83 \mathrm{ft} .10 \mathrm{in}$. \\
\hline Height & $\begin{array}{c}\text { (Overall) } 30 \mathrm{ft} .6 \mathrm{in} . \\
\text { (Doorsill) } 7 \mathrm{ft} .7 \mathrm{in} .\end{array}$ \\
\hline Weight & $\begin{array}{c}\text { (TOGW) } 320,000 \mathrm{lbs} . \\
\text { (Fuel) } 168,000 \mathrm{lbs} . \\
(\text { OEW }) 136,000 \mathrm{lbs} .\end{array}$ \\
\hline Cruise & $\mathrm{M}=1.7$ \\
& $\mathrm{~L} / \mathrm{D}=8.7$ \\
\hline Payload & $>5000 \mathrm{~nm}$ \\
\hline Range & \begin{tabular}{c} 
(Full carpet) $<85 \mathrm{PLdB}$ \\
\hline Boom Strength
\end{tabular} \\
\hline Ground Op & $\begin{array}{c}\text { (Wheelbase) } 91 \mathrm{ft} .3 \mathrm{in} . \\
\text { (Wheeltrack) } 14 \mathrm{ft} . \\
\text { (Turnover) } 60 \mathrm{deg} .\end{array}$ \\
\hline
\end{tabular}

presented in Figure 5.

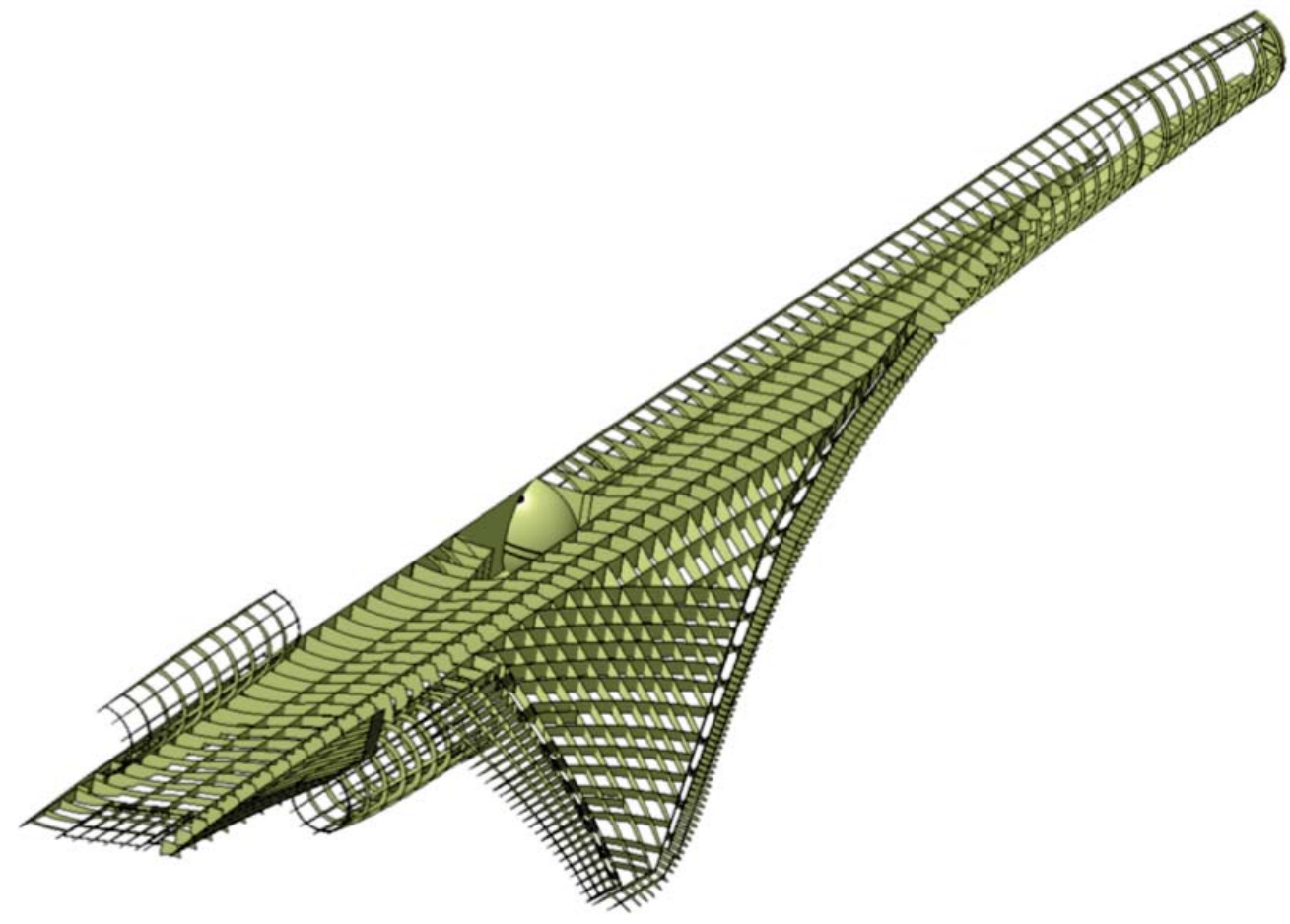

Figure 4. A view of the substructure of the $\mathrm{N}+2$ configuration.

Based on this structural layout, a detailed FEM was developed that captures realistic structural design constraints associated with this class of vehicles. A snapshot of the different sections of the $\mathrm{N}+2 \mathrm{FEM}$ is 
presented in Figure 6.

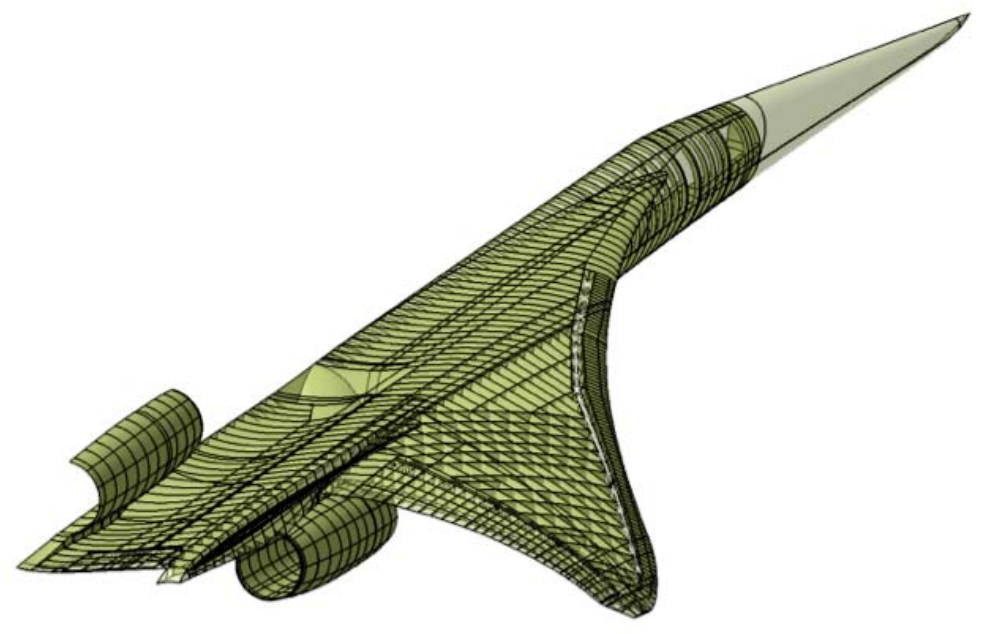

Figure 5. Structural layout of the $\mathrm{N}+2$ configuration. 


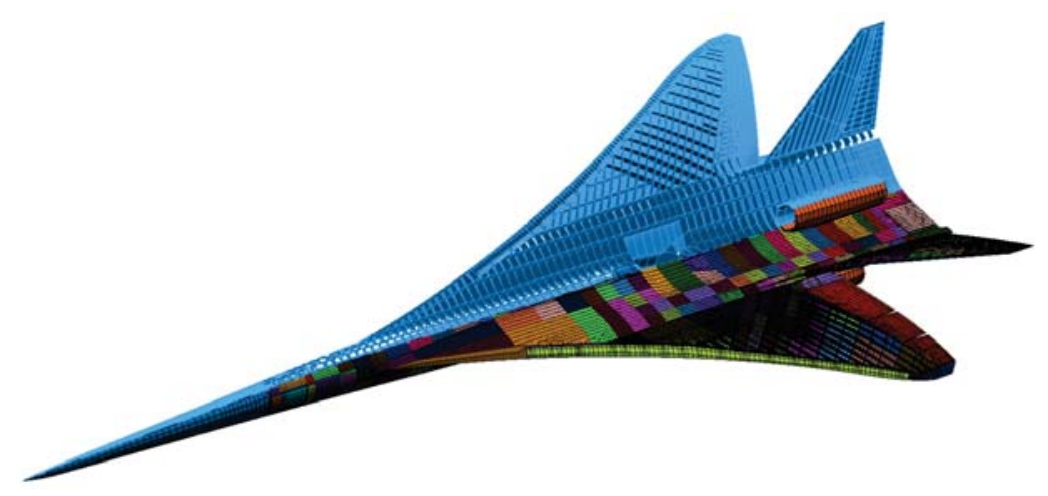

(a) Isometric view.

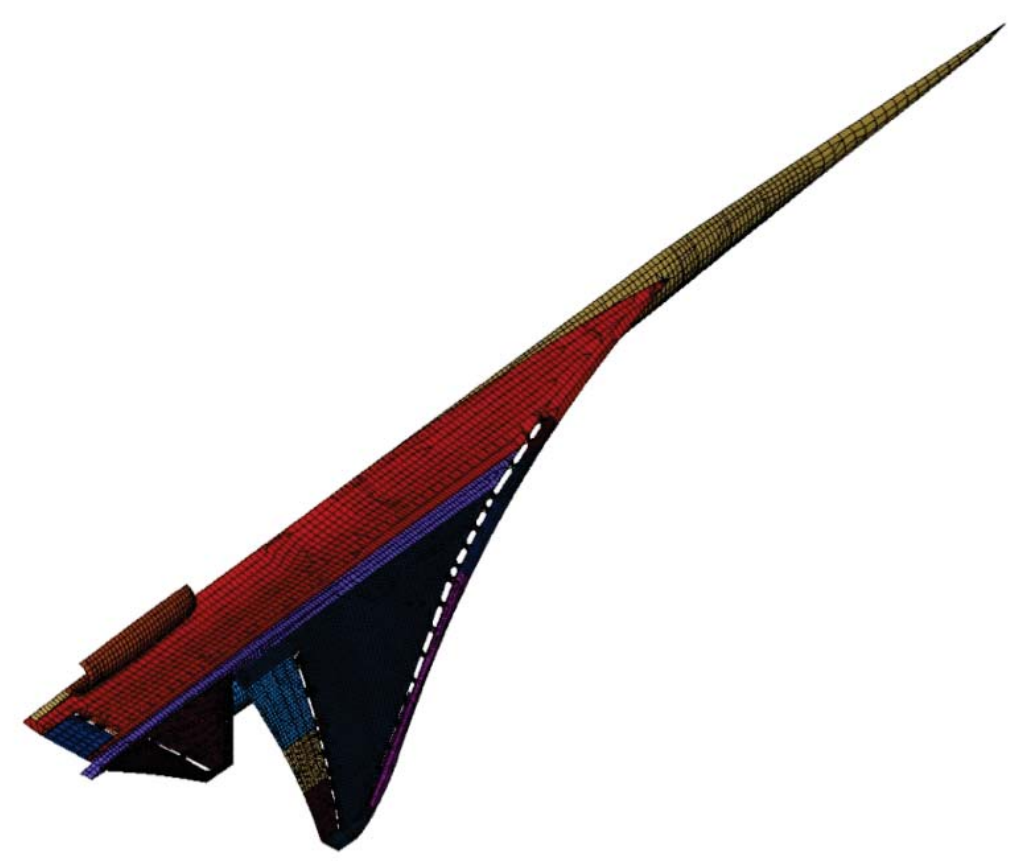

(b) Aft quarter.

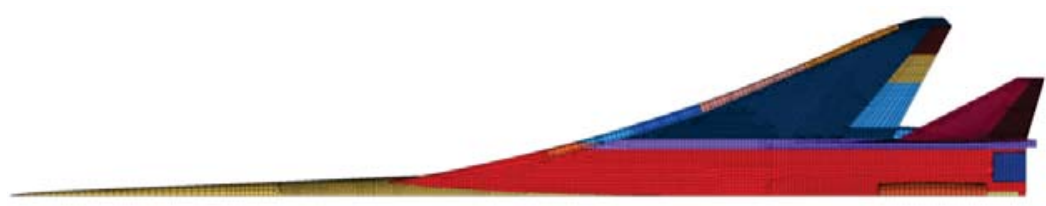

(c) Side view.

Figure 6. Different views of the $\mathrm{N}+2$ FEM.

The finite element model was sized using MSC.Nastran ${ }^{10}$ SOL200 assuming the implementation of composite structures. The majority of the FEM was discretized into constant property design zones, and the optimizer was allowed to adjust these properties using the design variables defined within these zones. Skins assumed a sandwich approach consisting of Graphite/BMI Unidirectional Tape with a honeycomb core, resulting in three independent design variables per zone $(0,+-45,90$ degree plies; core thickness remains constant in sizing). The design of the substructure also assumed a sandwich approach with Graphite/BMI Fabric facesheets. The design approach for the substructure assumed a quasi-isotropic laminate, resulting in one design variable per zone. Core thickness for the substructure also remained constant during sizing. A representative mass distribution was also developed and applied that accounted for systems, payload, and various fuel states. Buckling was included during the optimization by coupling an in-house analysis code 
along with MSC.Nastran SOL200.

Reasonable thicknesses were obtained through optimization for a majority of the substructure, with a few thickness concentrations being addressed by design zone refinement. The resulting structural design was very flexible, with the first eleven elastic modes having frequencies below ten $\mathrm{Hz}$. The first eight flexible symmetric modes are presented in Figure 7 and Figure 8.

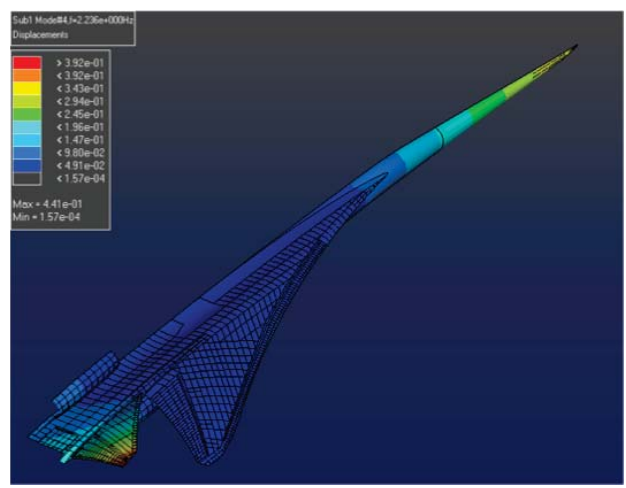

(a) Mode 4, Fuselage Bending, $2.24 \mathrm{~Hz}$

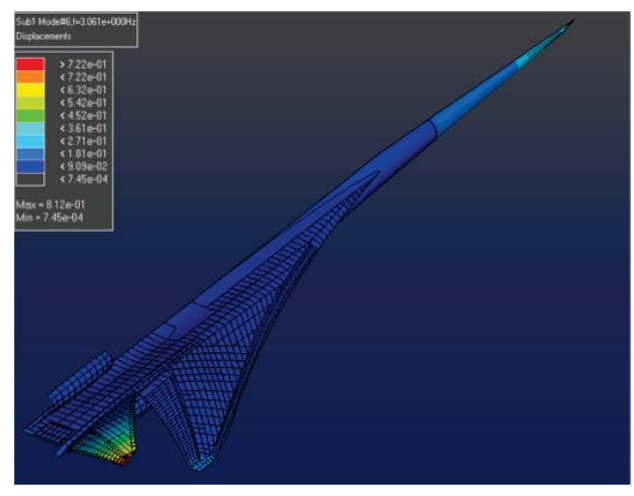

(c) Mode 6, Tail Bending, $3.06 \mathrm{~Hz}$

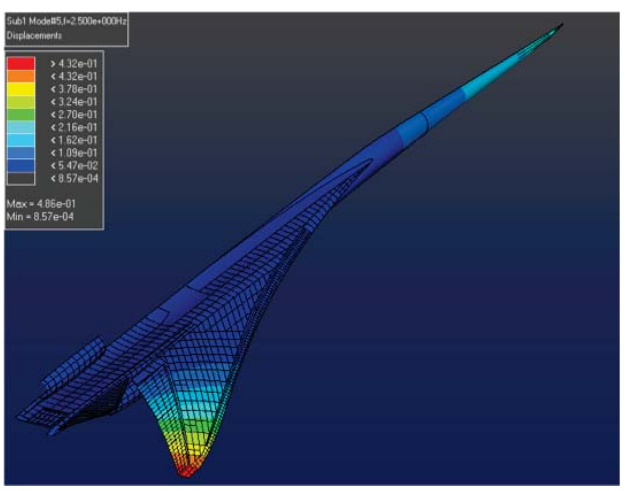

(b) Mode 5, Wing Bending, $2.50 \mathrm{~Hz}$

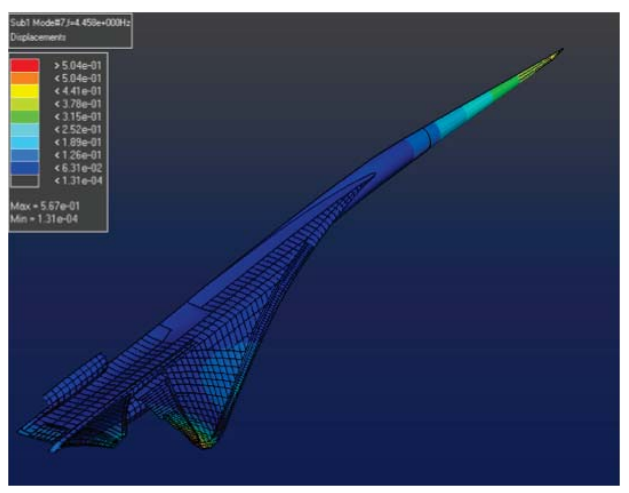

(d) Mode 7, Wing Tip Bending-TorsionFuselage 2nd Bending, $4.46 \mathrm{~Hz}$

Figure 7. First four symmetric flexible modes, Modes 4-7. 


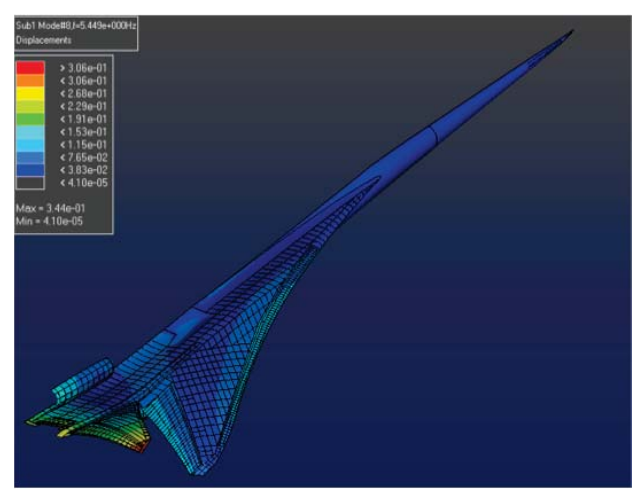

(a) Mode 8, Wing Torsion-Aft Deck-Tail Bending, $5.45 \mathrm{~Hz}$

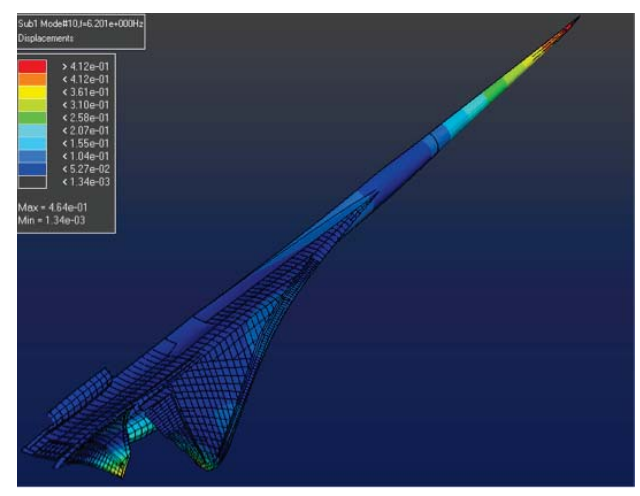

(c) Mode 10, Forward Fuselage Bending-WingTail Tip Out of Phase, $6.20 \mathrm{~Hz}$

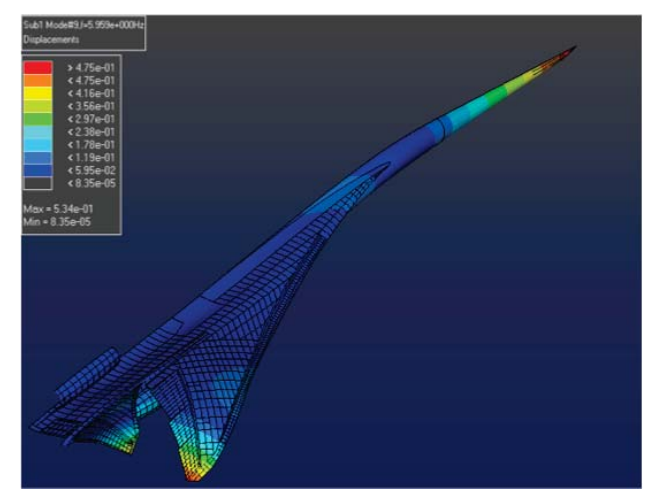

(b) Mode 9, Forward Fuselage Bending-WingTail Tip In Phase, $5.96 \mathrm{~Hz}$

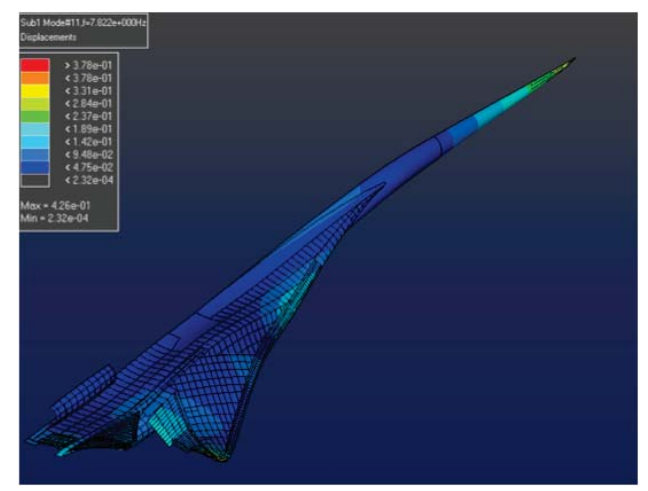

(d) Mode 11, Higher Order Fuselage Bending, $7.82 \mathrm{~Hz}$

Figure 8. Next four symmetric flexible modes, Modes 8-11.

\section{Linear Aeroelastic Analyses}

The $\mathrm{N}+2$ configuration FEM is being used to perform linear and nonlinear AE analyses. Linear AE analyses include the generation of linear subsonic frequency-domain unsteady aerodynamics using the doublet lattice method. Linear supersonic frequency-domain unsteady aerodynamics were generated using the Zona method. Presented in Figure 9 is a planform view of the doublet lattice aerodynamic box layout consisting of 1930 boxes.

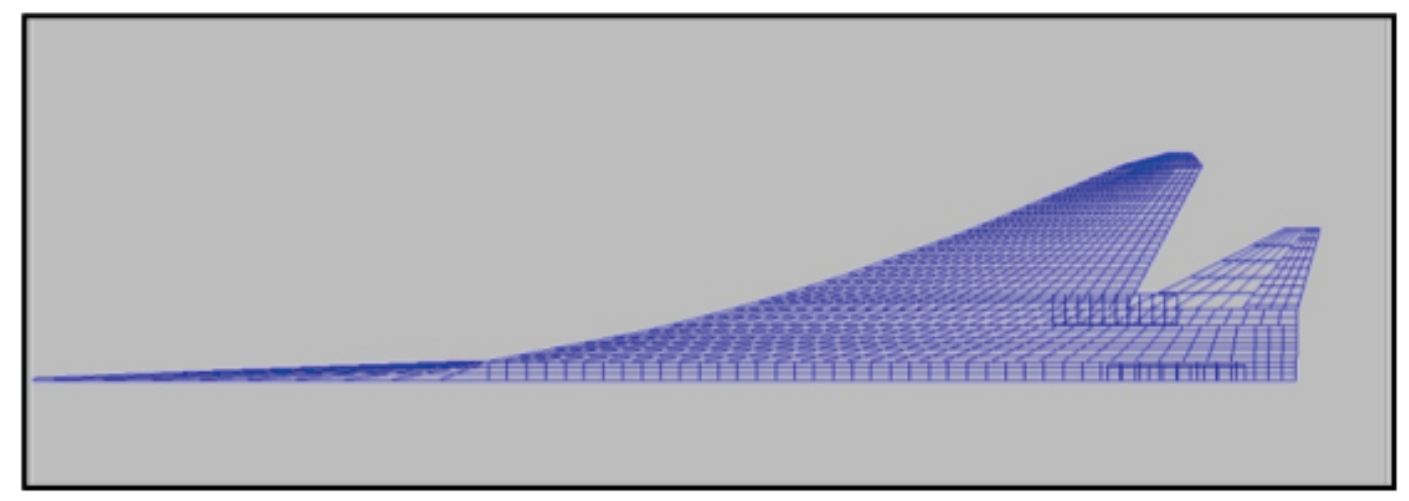

Figure 9. Planform view of the doublet lattice model.

Presented in Figure 10 is a view detailing all of the control surfaces defined within the doublet lattice model. Several analyses were performed to establish linear trim values at several flight conditions, although 


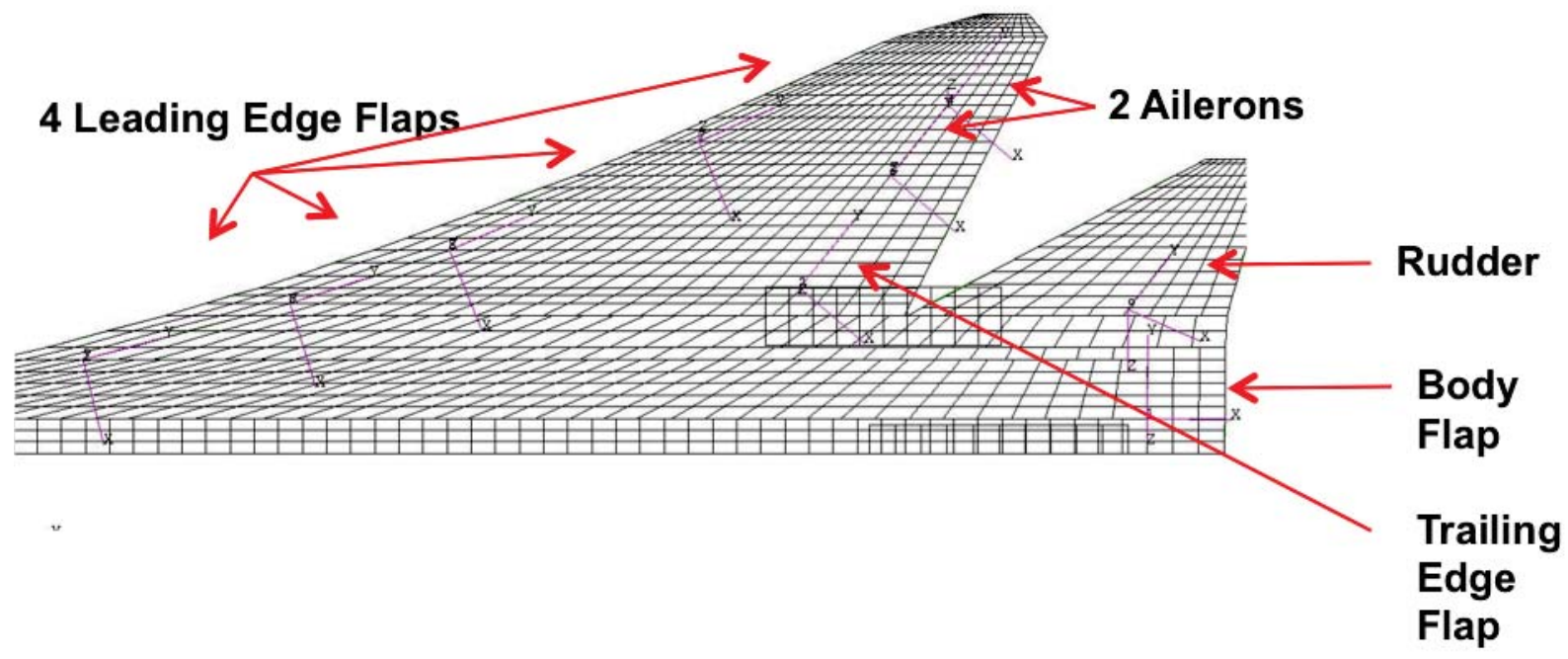

Figure 10. View of the control surface definitions for the doublet lattice model.

In addition, linear stability and control analyses were performed using the doublet lattice model for subsequent comparison with available wind-tunnel data for a similar configuration. Figure 11 presents a sample of a rigid aerodynamic response calculated based on a combination of control surface deflections. These computations were performed in order to validate the overall modeling of the linear aerodynamic model.

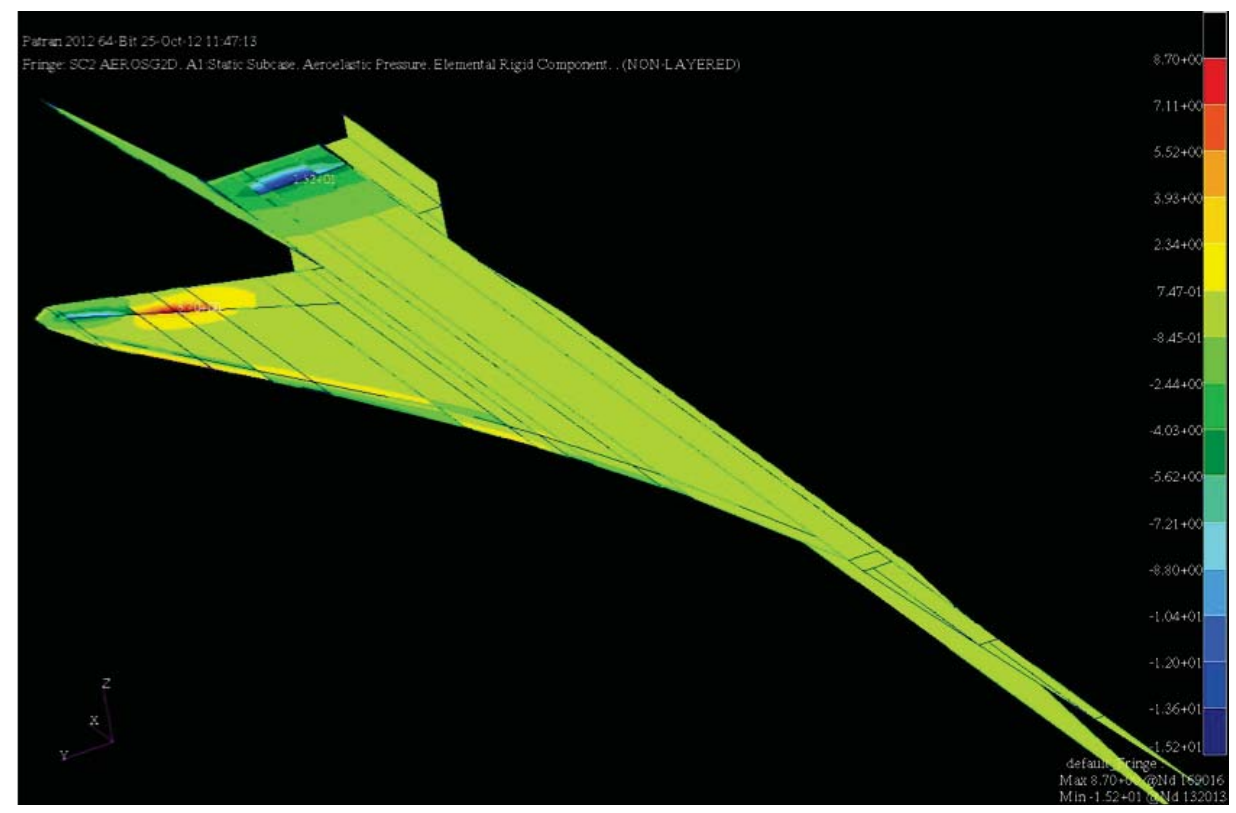

Figure 11. Effect of control surface deflections for the doublet lattice model.

Validation of the linear aerodynamic model was performed by comparing linear stability derivatives with available experimental results (wind tunnel test data). Presented in Figure 12 is a comparison of lift coefficient due to angle of attack (CL-alpha curves) from the linear aerodynamic model and from wind-tunnel data for the configurations with and without nacelles. There is good comparison between the predicted lift coefficient due to angle of attack computed using the linear aerodynamic model and the measured wind-tunnel data. 
It is also interesting to note that there is no noticeable effect of the nacelles in the linear aerodynamic model on the CL-alpha curves. This result may be different for results obtained using CFD-based methods.

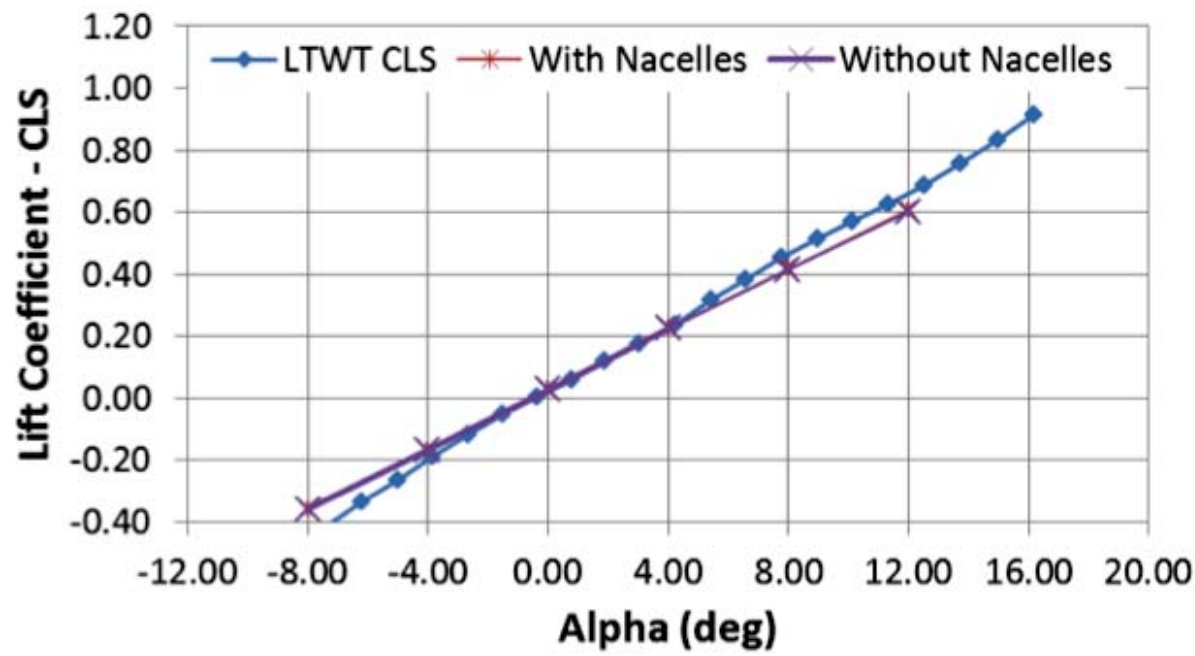

Figure 12. Comparison of CL-alpha curves from linear aerodynamic model and wind-tunnel data at low speed (M=0.14), with and without nacelles.

Presented in Figure 13 is a comparison of pitching moment due to angle of attack computed using the linear aerodynamic model and measured in the wind tunnel. In this case, the comparison is not as good as it is for lift coefficient over a broad range of angles of attack. Consistent with the results presented for the lift coefficient result, there is no noticeable effect of nacelles on pitching moment as a function of angle of attack. This variation in pitching moment will need to be evaluated upon the application of CFD-based methods to better understand the reasons for the discrepancy.

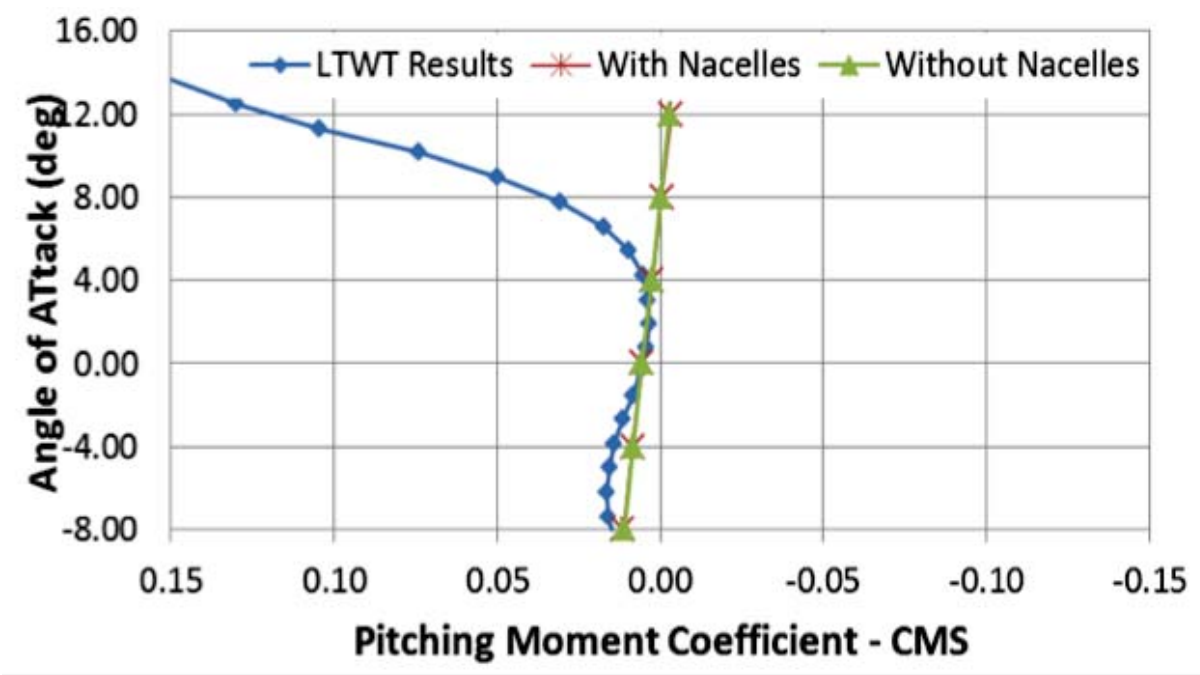

Figure 13. Comparison of CM-alpha from linear aerodynamic model and wind-tunnel data at low speed (M=0.14), with and without nacelles.

Presented in Figure 14 is a comparison of the lift-curve slope computed using the linear aerodynamic model and the lift-curve slope from wind-tunnel test. As can be seen, the value of lift-curve slope computed using the linear aerodynamic model is in excellent agreement with the lift-curve slope computed from measured values of lift in the wind tunnel. 


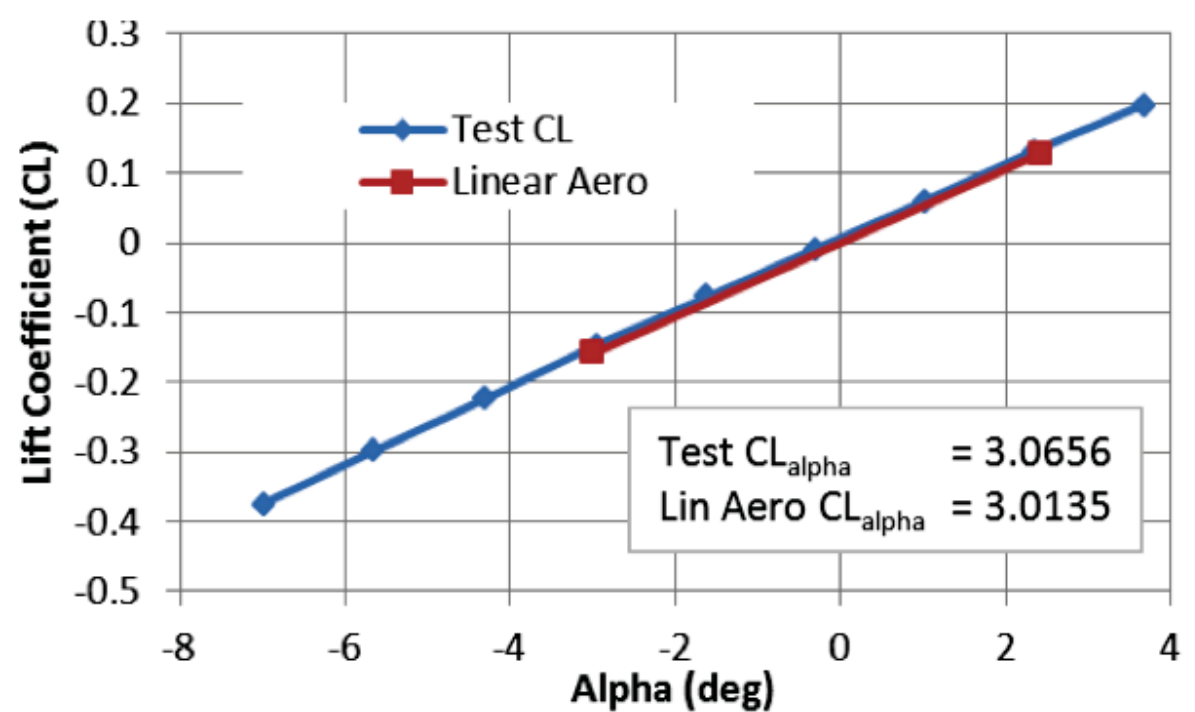

Figure 14. Closer view of the comparison of CL-alpha curves from linear aerodynamic model and wind-tunnel data at low speed $(\mathrm{M}=0.14)$, with and without nacelles.

Preliminary flutter results, computed using linear subsonic and supersonic unsteady aerodynamics, are presented in Figure 15. The region below the Mission Dynamic Pressure (black line) defines the flight envelope of the vehicle. The Mission Dynamic Pressure-15\% Margin (red line) defines a 15\% increase above the flight envelope. The ZFW refers to the Zero Fuel Weight condition; DTOW refers to the Design Take-Off Weight condition for a previous version of the FEM; DTOW2-FWD refers to a second iteration of the FEM with a forward CG position; DTOW2-AFT refers to the same second iteration of the FEM but with an aft CG position; and FEM014-DTOW refers to the most recently sized and updated version of the FEM.

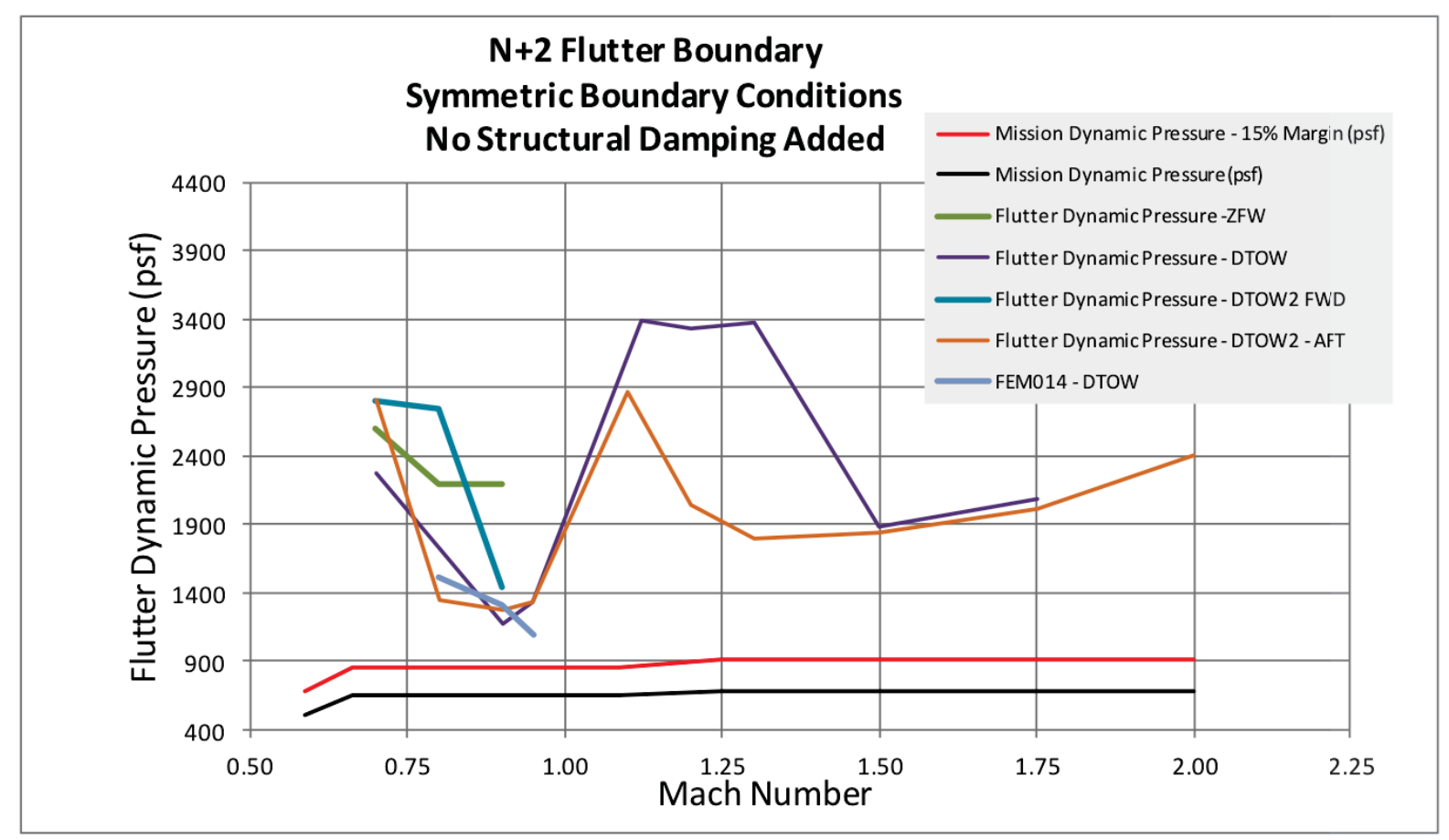

Figure 15. Flutter boundaries based on linear unsteady aerodynamics.

It can be seen that the most recent version of the FEM yields the lowest flutter boundaries so far for subsonic Mach numbers. It should be kept in mind that flutter dynamic pressures predicted by linear 
aerodynamics are less reliable in the transonic regime and are generally non-conservative. Exactly which Mach numbers define the transonic regime for this configuration is still to be determined. For these reasons, the use of CFD-based aeroelastic analyses becomes a critical part of this research.

\section{CFD-Based Analyses}

Two CFD solvers were used to address the various goals of the $\mathrm{N}+2$ effort. CFD ++ from Metacomp Technologies was used for sonic boom analysis with a hybrid tet/hex grid tailored to efficiently propagate the sonic boom signatures to a sufficient distance for propagation to the ground. The Euler equations were solved for full-scale sonic boom analysis due to the relatively small size of the boundary layer at high Reynolds number, but Navier Stokes analysis was found to be necessary for wind-tunnel sonic boom prediction. For CFD-based loads, Splitflow ${ }^{11}$ - a Lockheed-Martin in-house cartesian Euler/Navier Stokes Solver, was used to predict trim and aeroelastic effects on the load distribution. A Lockheed-Martin in-house modal-based linear structural analysis (LMMS) was used to perform the structural analysis and model control surface deflections. MDICE ${ }^{12}$ (the MultiDisciplinary Computing Environment) was used to coordinate the simulation and transfer loads and displacements between Splitflow and LMMS.

In addition to linear aeroelastic analyses, CFD-based aeroelastic analyses using NASA-developed structured $\left(\mathrm{CFL} 3 \mathrm{Dv} 6^{13,14}\right)$ and unstructured $\left(\mathrm{FUN}^{2} \mathrm{D}^{15}\right)$ CFD codes is underway. Unsteady aerodynamic and aeroelastic reduced-order models (ROMs) will also be computed and used to generate aeroelastic root locus plots in order to identify the critical flutter mechanisms at several Mach numbers.

\section{V.A. Structured Grids}

The CFL3Dv6 code solves the three-dimensional, thin-layer, Reynolds averaged Navier-Stokes equations with an upwind finite volume formulation. The code uses third-order upwind-biased spatial differencing for the inviscid terms with flux limiting in the presence of shocks. Either flux-difference splitting or flux-vector splitting is available. The flux-difference splitting method of Roe ${ }^{16}$ is employed in the present computations to obtain fluxes at cell faces. There are two types of time discretization available in the code. The first-order backward time differencing is used for steady calculations while the second-order backward time differencing with subiterations is used for static and dynamic aeroelastic calculations. Furthermore, grid sequencing for steady state and multigrid and local pseudo-time stepping for time marching solutions are employed.

One of the important features of the CFL3D code is its capability of solving multiple zone grids with one-to-one connectivity. Spatial accuracy is maintained at zone boundaries, although subiterative updating of boundary information is required. Coarse-grained parallelization using the Message Passing Interface (MPI) protocol can be utilized in multiblock computations by solving one or more blocks per processor. When there are more blocks than processors, optimal performance is achieved by allocating an equal number of blocks to each processor. As a result, the time required for a CFD-based aeroelastic computation can be dramatically reduced.

In this paper, multiblock MPI parallel aeroelastic computations, including flutter, for a flexible, semispan supersonic configuration are performed using 28 flowfield blocks. To achieve an optimal division of grid points, it is necessary to place flow field block boundaries near a moving solid surface (the wing). The multiblock boundary and interior movement scheme allows the user to place block boundaries near surfaces as necessary for optimal parallelization. Boundaries interior to the fluid domain near a moving surface respond to the local surface motion. As the wing moves, block boundaries move to maintain integrity of block interfaces and the airfoil surface.

Because the CFD and computational structural mechanics (CSM) meshes usually do not match at the interface, CFD/CSM coupling requires a surface spline interpolation between the two domains. The interpolation of CSM mode shapes to CFD surface grid points is done as a preprocessing step. Modal deflections at all CFD surface grids are first generated. Modal data at these points are then segmented based on the splitting of the flow field blocks. Mode shape displacements located at CFD surface grid points of each segment are used in the integration of the generalized modal forces and in the computation of the deflection of the deformed surface. The final surface deformation at each time step is a linear superposition of all the modal deflections.

Presented in Figures 16 to 21 are several views of the structured surface grid currently under development for use with the CFL3Dv6 code. The structured surface grid has about 190,000 grid points. There will be 
at least two structured grids generated: one without engines and one with engines. Although the engines are always included via the mode shapes, the aerodynamic representation of the engines (in a grid) will not be included in one of the structured grids generated. The reason for generating a grid without the engines is based on prior experience. In the past, the creation of a structured grid for this class of vehicles with the inclusion of engines posed difficulties when splining the mode shapes onto the surface grid in the region of the engines. Whether or not the inclusion of engines in a structured grid will be a difficulty for this configuration is to be evaluated during this research.

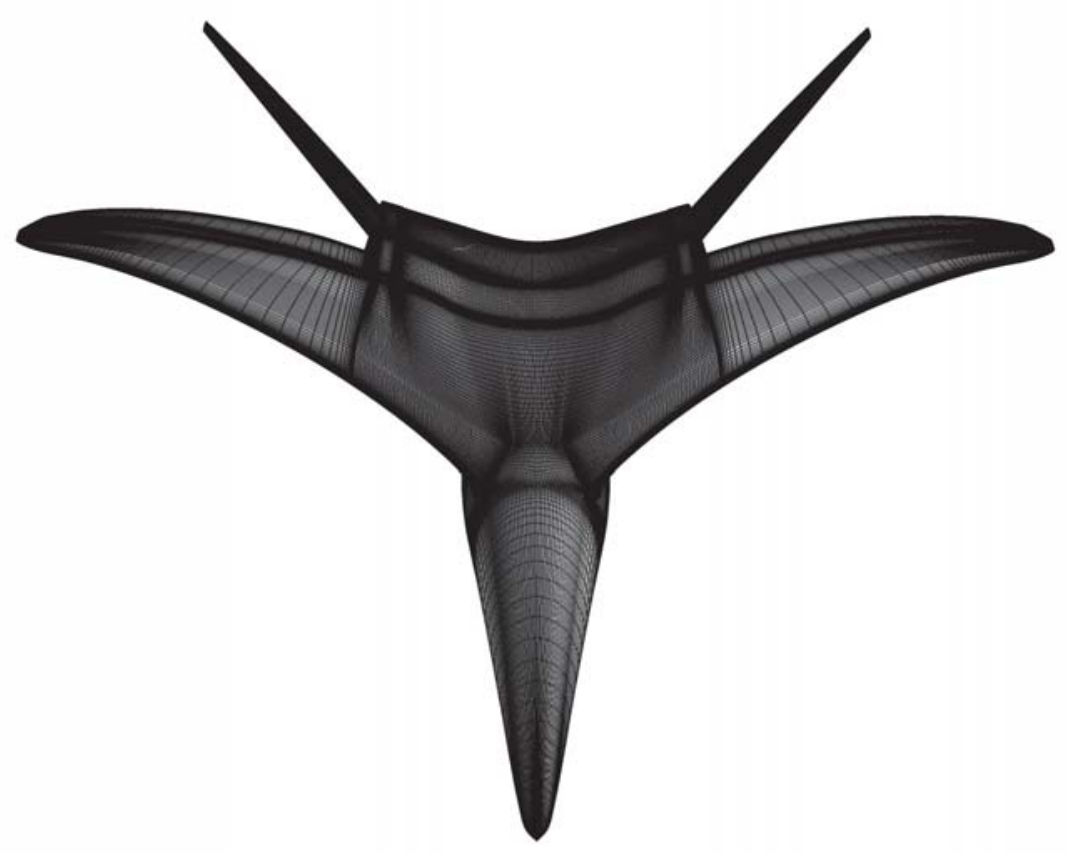

Figure 16. Forward and top view of the structured grid. 


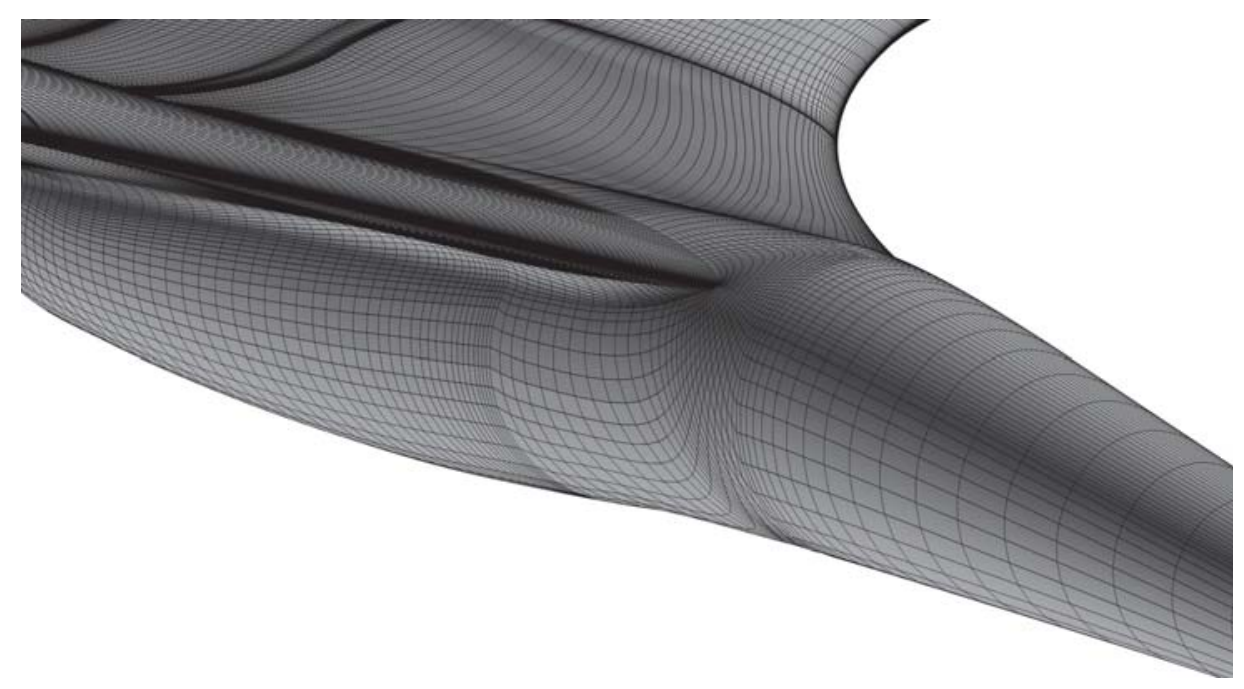

Figure 17. Zoomed-in isometric view of the structured grid.

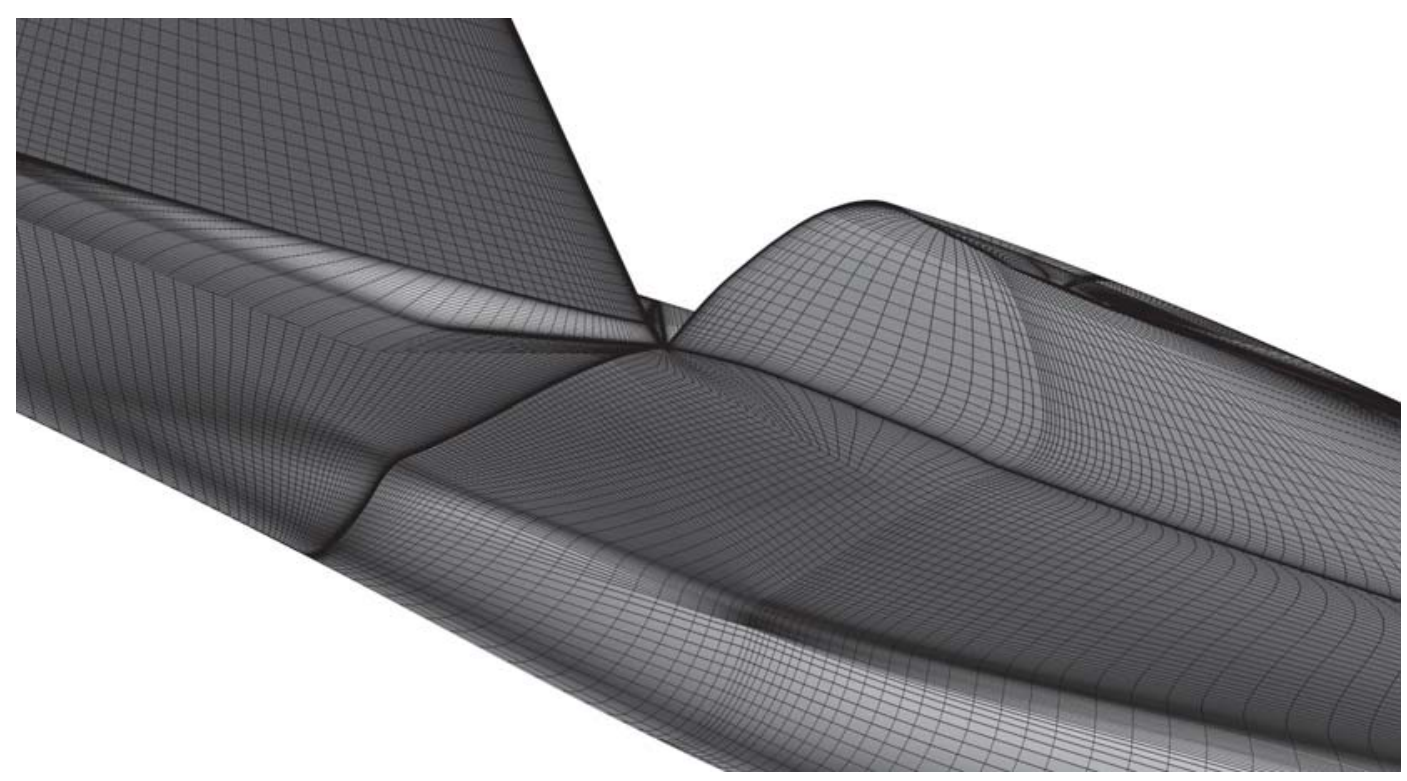

Figure 18. Zoomed-in aft view of tail region of the structured grid. 


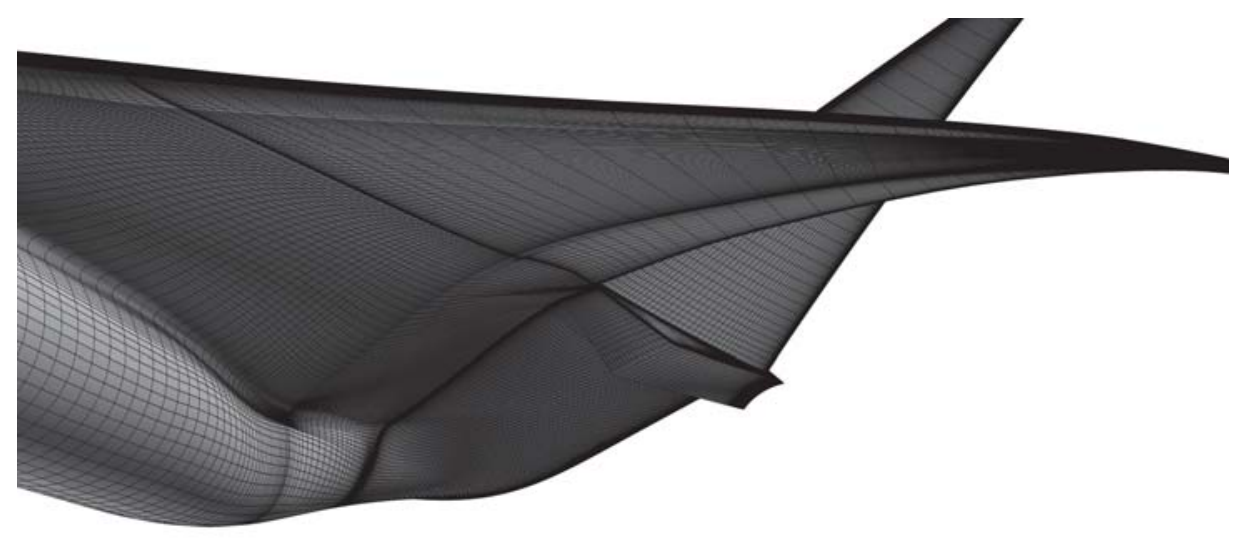

Figure 19. Zoomed-in front view of tail region of the structured grid.

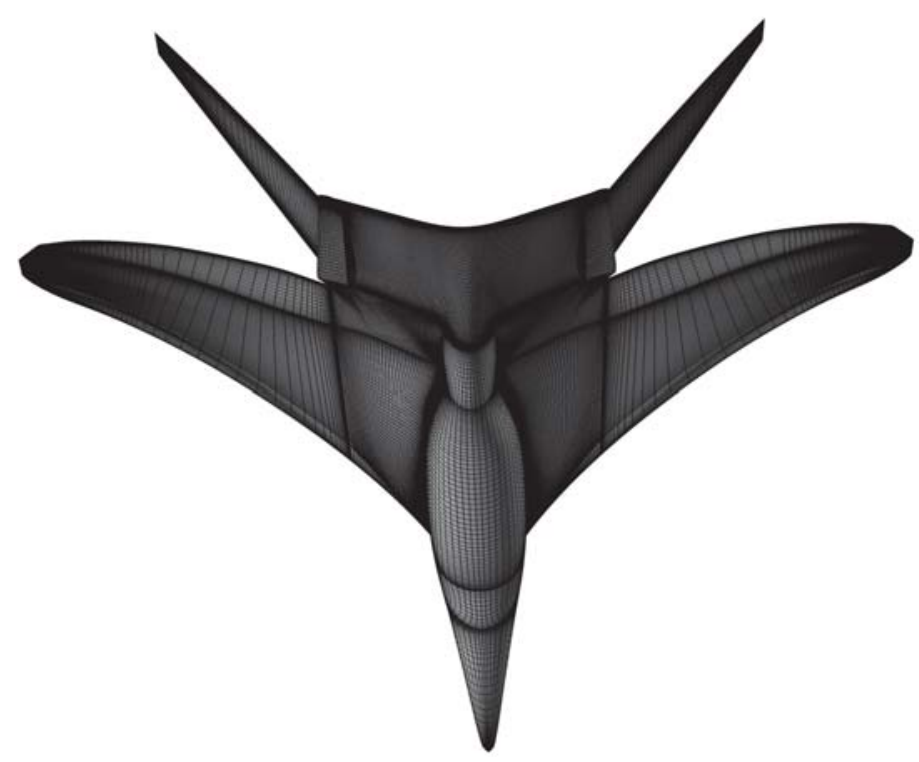

Figure 20. Bottom view of the structured grid. 


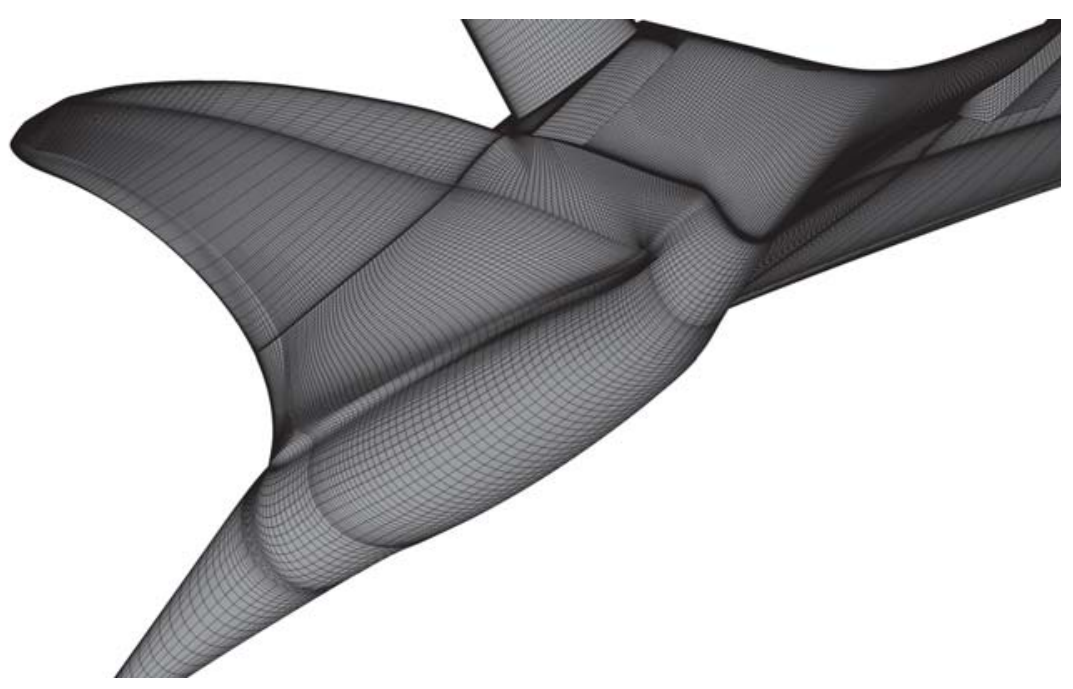

Figure 21. Zoomed-in aft view of the structured grid.

\section{V.B. Unstructured Grids}

Multiple unstructured grids (inviscid, viscous, with and without engines) of the $\mathrm{N}+2$ configuration are being generated for use with the FUN3D code. Some of these grids have already been generated while others are still being developed. The unstructured mesh solver used for this study is FUN3D. Within the code, the unsteady Navier-Stokes equations are discretized over the median dual volume surrounding each mesh point, balancing the time rate of change of the averaged conserved variables in each dual volume with the flux of mass, momentum and energy through the instantaneous surface of the control volume. Additional details regarding the aeroelastic capability within the FUN3D code can be found in the references. ${ }^{15}$

Presented in Figure 22 is a forward view of the viscous unstructured surface grid currently. Figure 23 presents a zoomed-in front view of the engines. If inclusion of the engines proves too demanding for splining of the mode shape for subsequent aeroelastic analyses, an unstructured grid without engines may be generated.

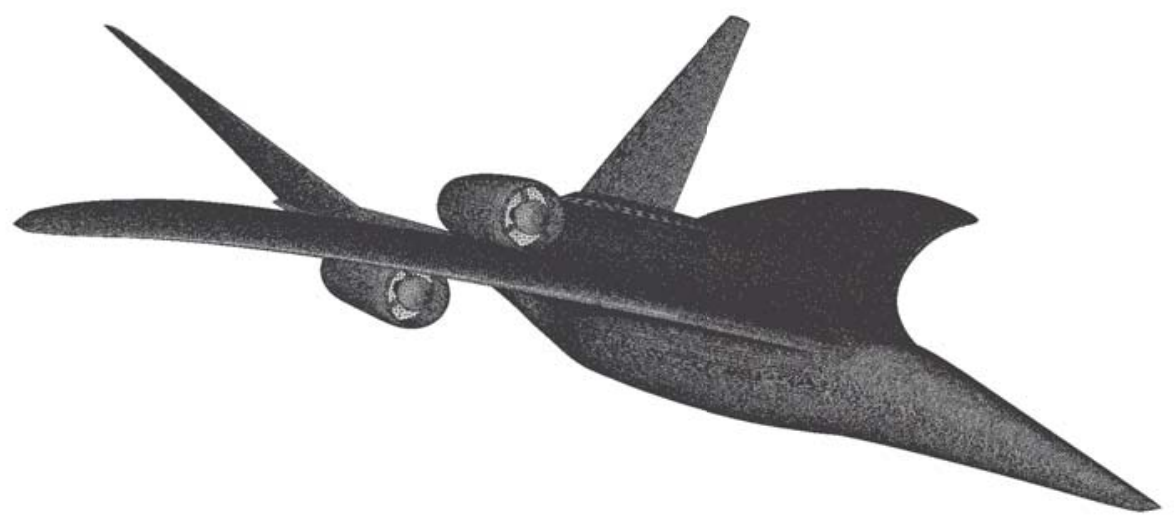

Figure 22. Forward view of the unstructured grid. 


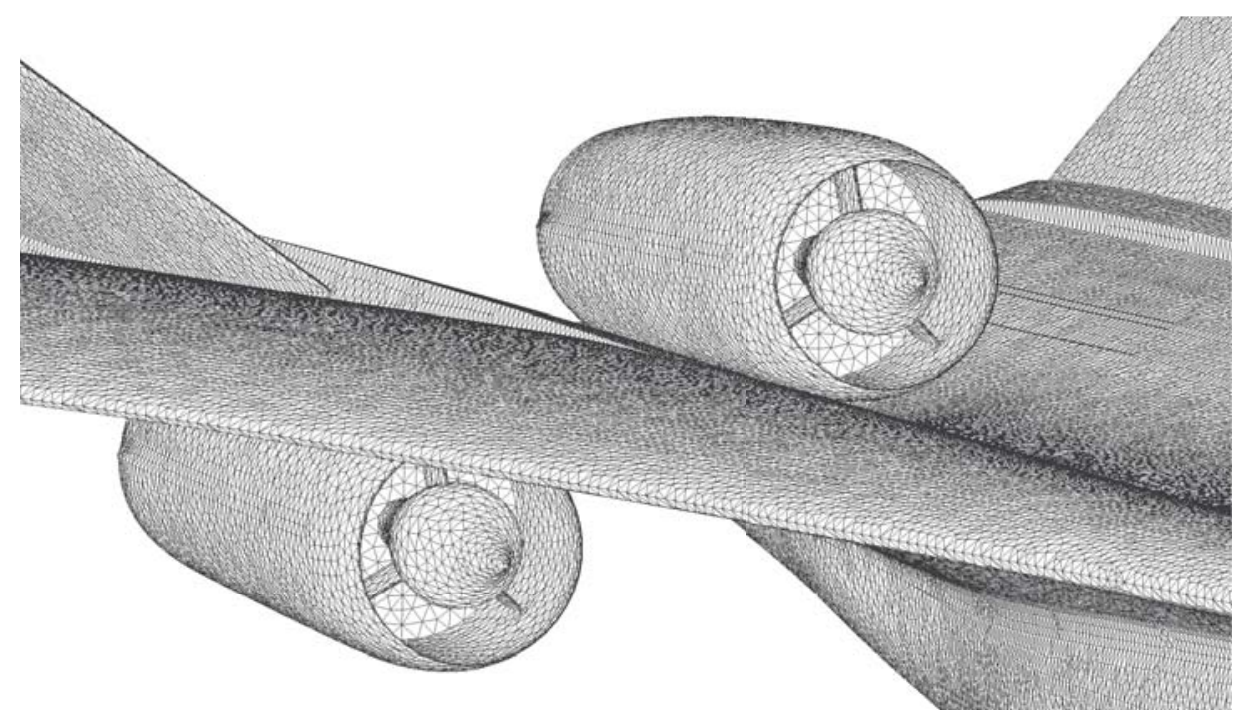

Figure 23. Zoomed-in view of the engines in the unstructured grid.

Figure 24 presents a zoomed-in view of the nose of the fuselage showing some detail in the region of the wing-fuselage interface that is an important region for capturing complex flows. Figure 25 presents a rear view of the unstructured surface grid where the complexity for the configuration is evident. A zoomed-in view of the engines from the rear is presented as Figure 26 where the detail associated with the engines is again evident. The half-plane unstructured surface grid has 298,085 points and 555,710 cells.

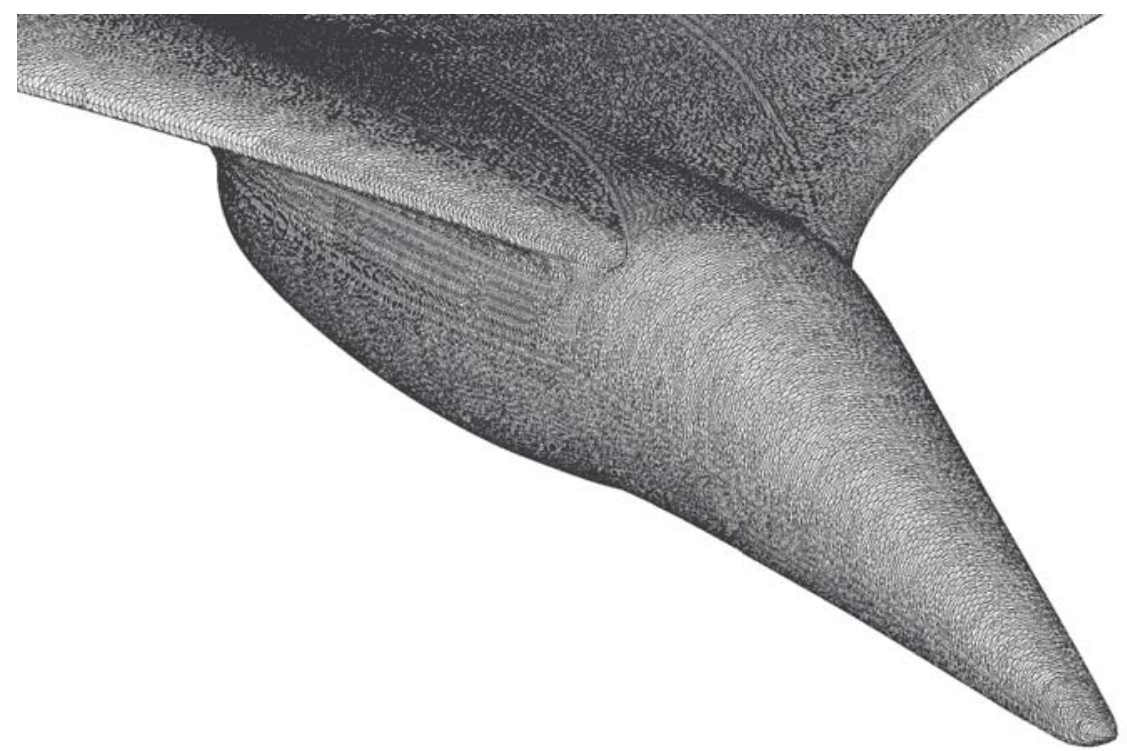

Figure 24. Zoomed-in view of the forward fuselage in the unstructured grid. 


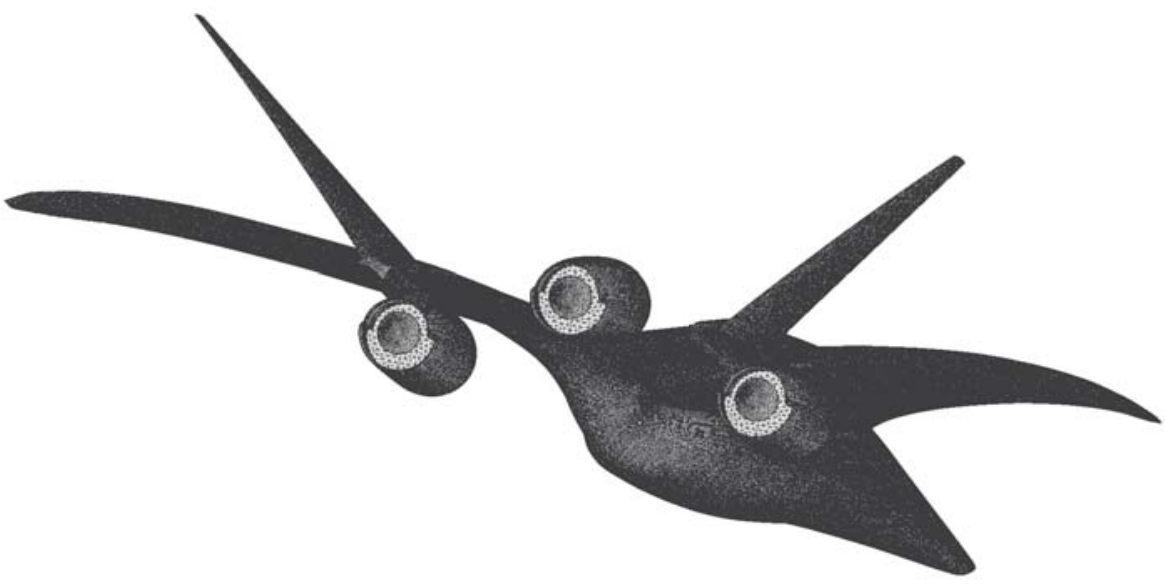

Figure 25. Rear view of the unstructured grid.

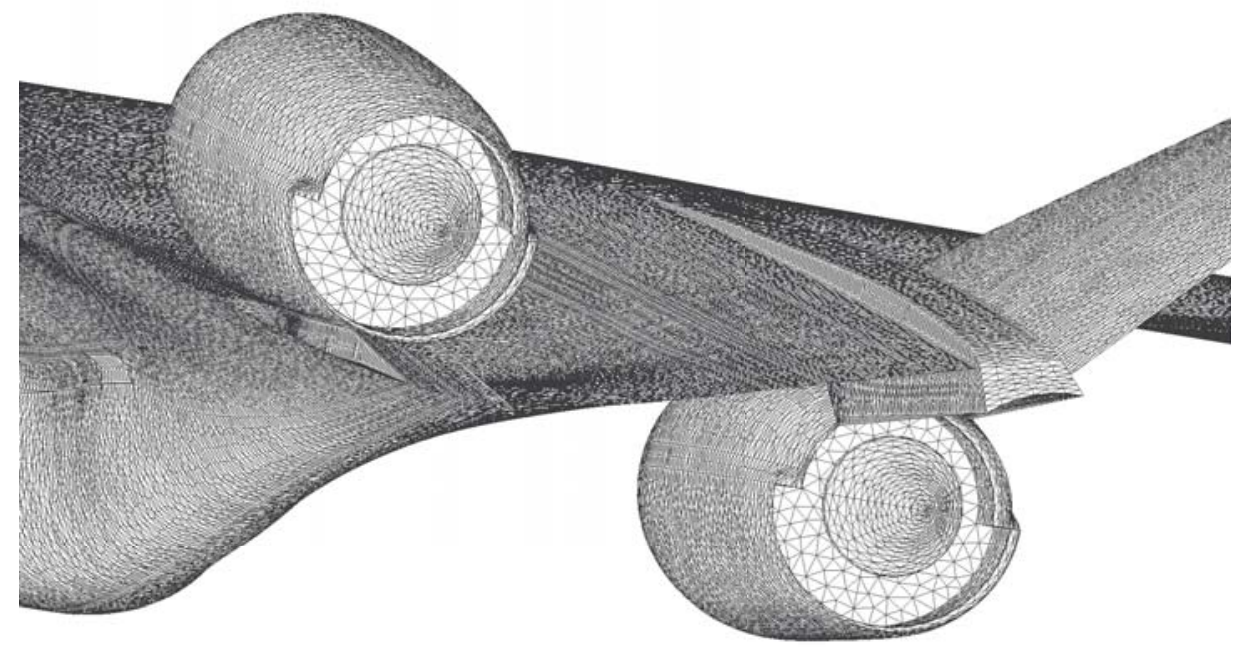

Figure 26. Zoomed-in rear view of the engines in the unstructured grid.

\section{V.C. CFD-Based Loads}

Various linear and CFD-based aeroelastic analyses were performed to assess the impact of structural flexibility on trim state and flight loads. Presented in Figure 27 is a steady-state CFD trim loads analysis of the N+2 configuration at $\mathrm{M}=1.41$ performed by Lockheed-Martin. The strong vortical flows are evident in this figure and is indicative of the importance of using CFD-based analyses to more accurately predict these types of flows. 


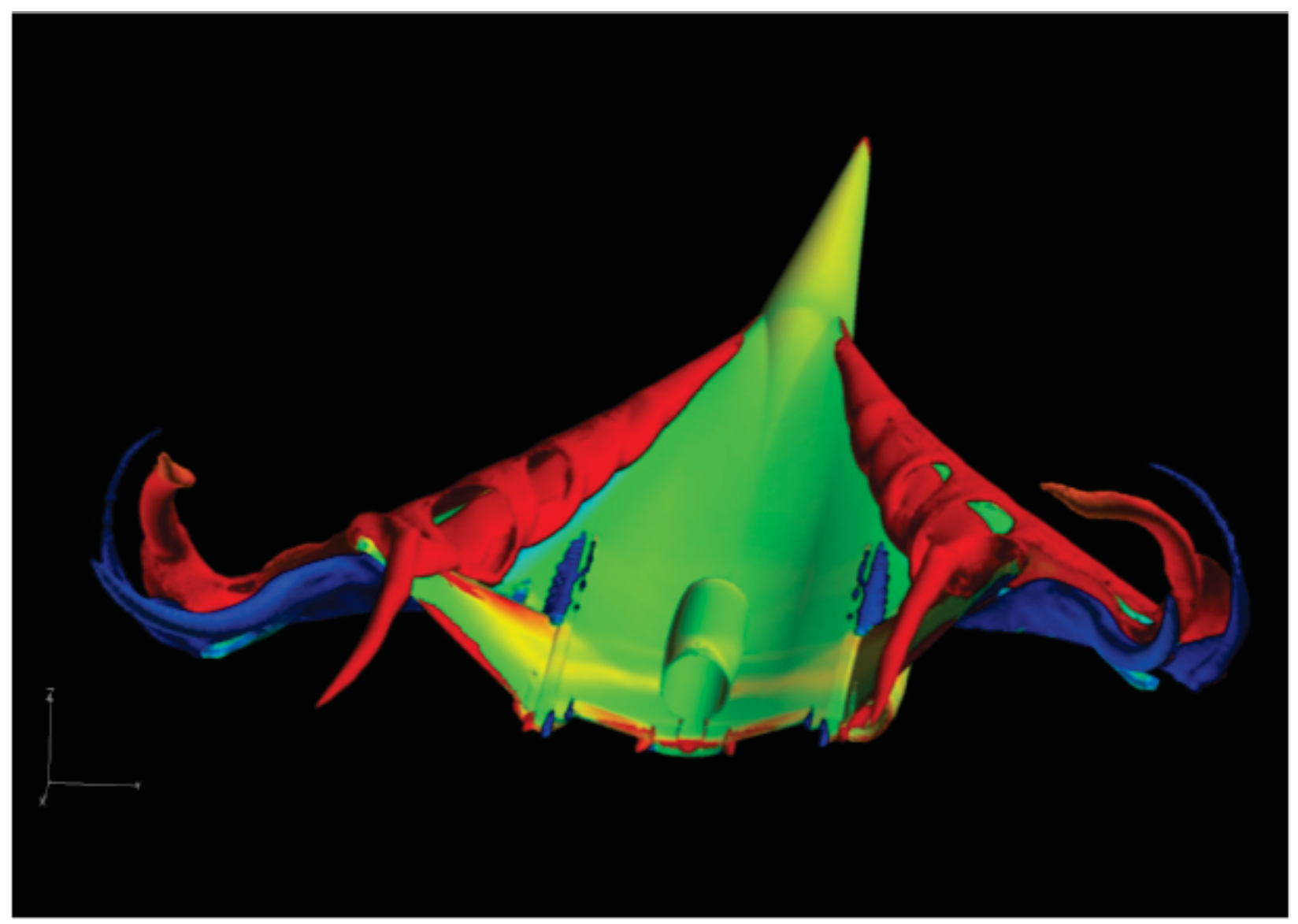

Figure 27. Lockheed-Martin CFD-based trim loads analysis at $M=1.41$, alpha=12 degrees.

Presented in Figure 28 is a steady-state inviscid CFD loads analysis of the $\mathrm{N}+2$ configuration at $\mathrm{M}=1.7$ performed by NASA using the FUN3D code. These preliminary results are being used for grid refinement and to identify critical flow regions on the configuration. 


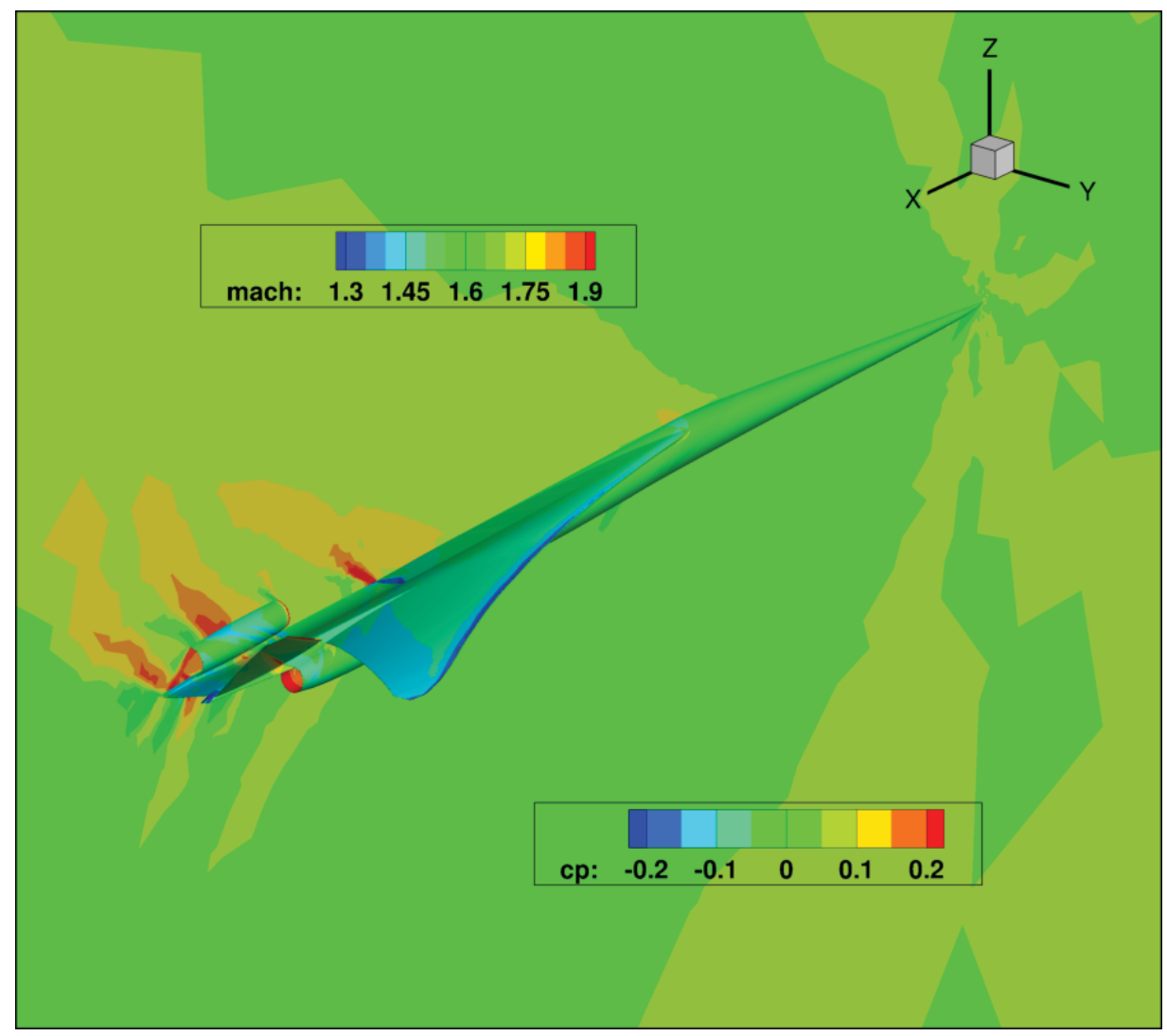

Figure 28. NASA inviscid CFD-based loads analysis at $M=1.70$, alpha=0 degrees.

\section{APSE}

A significant component of the High Speed ASE project is the development of AeroPropulsoServoElasticity (APSE) models. An APSE model simulates the dynamic interactions between the airframe and the propulsion system in a closed-loop fashion. An APSE model includes a traditional ASE (airframe) math model, a dynamic engine model, and all relevant interconnections between these two dynamic systems.

The development of an APSE model has not been trivial as these types of models currently do not exist due to an assumption that these two dynamic systems (flexible airframe and engine) do not interact in a significant manner. However, due to the increased flexibility and very tight systems integration requirements that can be expected for advanced supersonic configurations, this assumption may not be completely true.

The development and application of an APSE model would enable the simulation of airframe flexibility and its effects on propulsion (thrust) performance as well as the effect of thrust variations (frequency content, for example) on the airframe's flexible structure.

A simplified, proof-of-concept APSE model was recently developed under the High Speed ASE project. Presented in Figure 29 is a schematic of this simplified APSE system. ${ }^{17}$ This schematic identifies the airframe component (ASE Model), the dynamic engine model (Engine Model and related control system), and all the relevant interconnections, including the effects of atmospheric turbulence. 


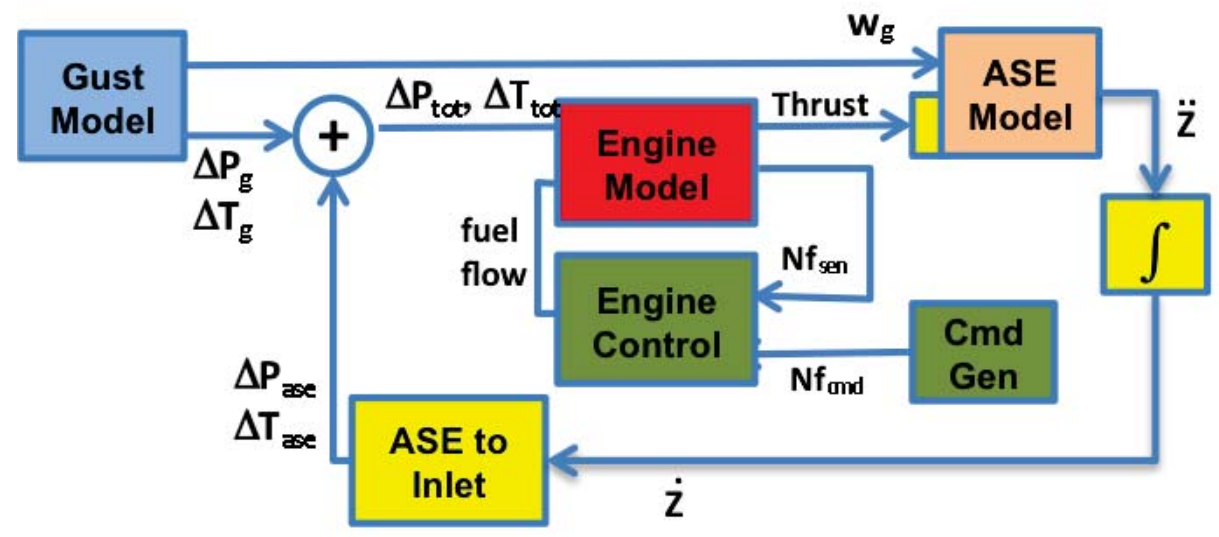

Figure 29. AeroPropulsoServoElastic (APSE) system schematic.

Presented in Figure 30 is a comparison of airframe accelerations generated with and without the closedloop coupling of the airframe and the engine. As can be seen from this simplified model, there is some interaction between the airframe and the engine that results in a difference in the dynamics of both systems. Continued development of this simplified model continues in order to improve its accuracy.

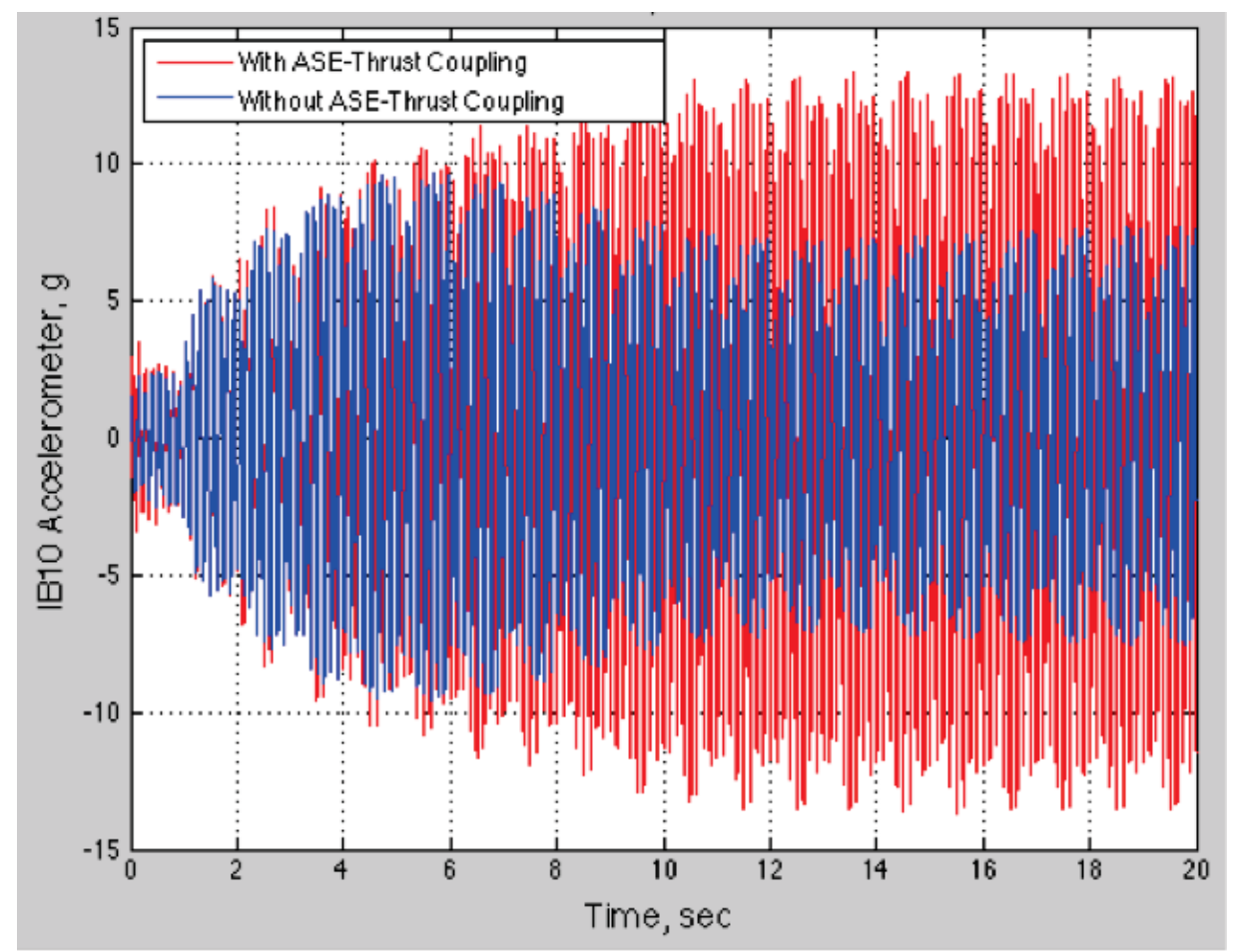

Figure 30. Acceleration with and without ASE-thrust coupling using APSE model.

\section{Concluding Remarks}

A summary of some of the major tasks being performed by NASA's High Speed ASE project was presented. The summary included a discussion of the low-boom N+2 configuration developed by LockheedMartin. A detailed finite element model (FEM) has been developed and was applied for generation of mode shapes and linear aeroelastic responses including flutter boundaries. CFD-based analyses were also discussed including the use of CFD methods for determining loads related to sizing of the structure. Structured and 
unstructured grids are being generated for subsequent use with the CFL3Dv6 and the FUN3D CFD codes. Finally, a brief overview of the ongoing work related to the development of APSE models was provided.

\section{References}

1 "Advanced Aeroservoelastic Testing and Data Analysis," AGARD Conference Proceedings 566, NATO, November 1995.

${ }^{2}$ Noll, T. E., "Aeroservoelasticity," 31st AIAA/ASME/ASCE/AHS/ASC Structures, Structural Dynamics and Materials Conference, No. 1990-29359, Long Beach, CA, April 1990.

${ }^{3}$ Sandford, M. C., Abel, I., and Gray, D. L., "Development and Demonstration of a Flutter-Suppression System Using Active Controls," NASA TR R-450, 1975.

${ }^{4}$ Abel, I., Perry, B., and Newsom, J. R., "Comparison of Analytical and Wind-Tunnel Results for Flutter and Gust Response of a Transport Wing with Active Controls," NASA TP 2010, 1982.

${ }^{5}$ Waszak, M. R., "Robust Multivariable Flutter Suppression for the Benchmark Active Control Technology (BACT) WindTunnel Model," Eleventh Symposium on Structural Dynamics and Control, May 12-14 1997.

${ }^{6}$ Perry, B., Cole, S. R., and Miller, G. D., "Summary of an Active Flexible Wing Program," Journal of Aircraft, Vol. 32, January-February 1995, pp. 10-15.

${ }^{7}$ Pendleton, E. W., Bessette, D., Field, P. B., and Miller, G. D., "Active Aeroelastic Wing Flight Research Program Technical Program and Model Analytical Development," Journal of Aircraft, Vol. 37, July-August 2000.

${ }^{8}$ Silva, W. A., Keller, D. F., Florance, J. R., Cole, S. R., and Scott, R. C., "Experimental Steady and Unsteady Aerodynamic and Flutter Results for HSCT Semispan Models," AIAA/ASME/ASCE/AHS/ASC 41st Structures, Structural Dynamics, and Materials Conference, No. 2000-1697, April 2000.

${ }^{9}$ Perry, B., Silva, W. A., Florance, J. R., Wieseman, C. D., Pototzky, A. S., Sanetrik, M. D., Scott, R. C., Keller, D. F., Cole, S. R., and Coulson, D. A., "Plans and Status of Wind-Tunnel Testing Employing an Aeroservoelastic Semispan Model," 48th AIAA/ASME/ASCE/AHS/ASC Structures, Structural Dynamics, and Materials Conference, No. AIAA Paper No. 2007-1770, Honolulu, HI, April 23-26 2007.

${ }^{10} \mathrm{http}: / /$ www.mscsoftware.com/product/msc nastran.

${ }^{11}$ Jr., S. L. K., "SPLITFLOW: 3D Unstructured Cartesian/Prismatic Grid CFD Code for Complex Geometries," AIAA Paper 95-0343, 1995.

${ }^{12}$ Multi-Disciplinary Computing Environment Users Guide Version 3.0, CFD Research Corporation, Huntsville, AL, 1998.

${ }^{13}$ Krist, S. L., Biedron, R. T., and Rumsey, C. L., "CFL3D User's Manual Version 5.0," Tech. rep., NASA Langley Research Center, 1997.

${ }^{14}$ Bartels, R. E., "Mesh Strategies for Accurate Computations of Unsteady Spoiler and Aeroelastic Problems," AIAA Journal of Aircraft, Vol. 37, 2000, pp. 521-525.

${ }^{15}$ Biedron, R. T. and Thomas, J., "Recent Enhancements to the FUN3D Flow Solver for Moving-Mesh Applications," 47th AIAA Aerospace Sciences Meeting, No. 2009-1360, Orlando, FL, Jan. 5-8 2009.

${ }^{16}$ Roe, P. L., "Approximate Riemann Solvers, Parameter Vectors, and Difference Schemes," Journal of Computational Physics, Vol. 43, 1981, pp. 357-372.

${ }^{17}$ Christhilf, D. M., Pototzky, A. S., and Stevens, W. L., "Incorporation of SemiSpan SuperSonic Transport (S4T) Aeroservoelastic Models into SAREC-ASV Simulation," AIAA Modeling and Simulation Technologies Conference, No. 2010-8099, Toronto, Ontario, Canada, Aug. 2010. 